\title{
TWO-PHASE FLOW PRESSURE DROP
}

OF HIGH QUALITY STEAM

J. M. Curtis

R. D. Coffield

DE-AC11-98PN38206

\section{NOTICE}

This report was prepared as an account of work sponsored by the United States Government. Neither the United States, nor the United States Department of Energy, nor any of their employees, nor any of their contractors, subcontractors, or their employees, makes any warranty, express or implied, or assumes any legal liability or responsibility for the accuracy, completeness or usefulness of any information, apparatus, product or process disclosed, or represents that its use would not infringe privately owned rights. 
Two-phase Flow Pressure Drop of High Quality Steam

John Curtis and Ron Coffield

Bechtel Bettis, Inc. P.O. Box 79 West Mifflin, Pa 15122

\begin{abstract}
Two-phase pressure drop across a straight test pipe was experimentally determined for high Reynolds $(\mathrm{Re})$ number steam flow for a flow quality ${ }^{1}$ range of 0.995 to 1.0 . The testing described has been performed in order to reduce uncertainties associated with the effects of two-phase flow on pressure drop. Two-phase flow develops in steam piping because a small fraction of the steam flow condenses due to heat loss to the surroundings. There has been very limited two-phase pressure drop data in open literature for the tested flow quality range. The two-phase pressure drop data obtained in this test has enabled development of a correlation between friction factor, Reynolds number, and flow quality.
\end{abstract}

\title{
1.0 INTRODUCTION
}

The purpose of the test was to quantify the effects of two-phase flow on pressure drop for high quality, high Reynolds number steam flow. To achieve this result, pressure drop along a straight test pipe was measured for steam flow with varying amounts of moisture.

The test was divided into two phases. The objective of Phase 1 testing was to minimize condensation. This was achieved by fully insulating the test pipe in order to minimize heat loss. The objective of Phase 2 testing was to vary the flow quality by controlled forced air cooling of the test pipe. For both phases of the test, steam mass velocity and pressure were varied to achieve a Reynolds number range of $0.7 \times 10^{6}-5.5 \times 10^{6}$.

\subsection{TEST CONFIGURATION}

The steam piping bench test was performed in the Bechtel Bettis steam test facility. Figure 2.1 shows the basic test configuration for Phase 1. All test section piping was made of two inch schedule 80 carbon steel with an inside diameter of 1.939 inches. The piping was commercial standard rough pipe with a measured roughness of 125 microinches.

The 2 test section piping was instrumented with a series of static pressure taps spaced 5 piping diameters apart. These taps were connected to pressure cells that measured pressure drop over 87.255 inches of straight pipe. All pressure taps in the test section piping were 0.028 inches in diameter. These were initially drilled to 0.024 inches and then increased in two 0.002 inch increments. This two step increase in the pressure tap I.D. from 0.024 to 0.028 inches was intended to maintain a sharp edge on the holes in order to minimize error in the static wall pressure measurements. To minimize flow maldistributions along the test section, a flow straightener was added prior to the test section. The flow straightener shown in Figure 2.1 used 35 holes with approximately a 0.248 inch inside diameter each. This design configuration was found to provide a fully developed turbulent velocity profile for high Reynolds number applications.

\footnotetext{
${ }^{1}$ Flow quality is defined as the weight fraction of the gas flowing in a two-phase mixture.
} 
To determine saturated steam properties, gage pressure cells were located at the venturi, tap 10 of the test section, and at the inlet of the steam generator.

The test section was passivated at $500^{\circ} \mathrm{F}$ for more than 120 consecutive hours before testing. This formed a layer of magnetite $\left(\mathrm{Fe}_{2} \mathrm{O}_{4}\right)$ on the surface which helped minimize other types of oxidation like hematite $\left(\mathrm{Fe}_{2} \mathrm{O}_{3}\right)$ which could have caused surface pitting. Magnetite forms an extremely thin (fractions of a mil) layer that tenaciously attaches at about the same thickness on all the exposed base metal.

The test instrumentation was configured to provide the following accuracies for measured test parameters:

- Flow rate (combined uncertainties including differential pressure reading, $\pm 3 \%$ line pressure reading, and venturi flow coefficient)

- Differential pressures $\pm 1.25 \%$

- Line pressure \pm 3 psig

The carbon steel test section piping inside diameter was corrected for thermal effects with the relationship:

$$
D=\left(1+\alpha\left(T_{S A T}-T_{A M B}\right)\right) * D_{M E A S}
$$

where:

$$
\begin{aligned}
& T_{S A T}=\text { operating temperature } \\
& T_{A M B}=\text { temperature that ID was measured }\left(=70^{\circ} \mathrm{F}\right) \\
& D_{M E A S}=\text { measured inside pipe diameter }\left(2^{\prime \prime} \text { Schedule } 80 \text { pipe }\right) \\
& \alpha \quad=\text { thermal expansion coefficient }
\end{aligned}
$$

The following values were used for the carbon steel thermal expansion coefficient:

Table 2.1

\begin{tabular}{|c|c|}
\hline $\begin{array}{c}\text { Temperature } \\
\left({ }^{\circ} \mathrm{F}\right)\end{array}$ & $\begin{array}{c}\alpha \times 10^{-6} \\
\left(\mathrm{in} / \mathrm{in} /{ }^{\circ} \mathrm{F}\right)\end{array}$ \\
\hline 70 & 6.07 \\
200 & 6.38 \\
300 & 6.60 \\
400 & 6.82 \\
500 & 7.02 \\
600 & 7.23 \\
\hline
\end{tabular}

For Phase 1 testing, the test section was fully insulated with 2 inch thick hard insulation. For Phase 2 testing, the hot caps were removed and a cooling jacket was installed to enclose the test section. The cooling jacket was a sealed 10" square metal duct that was attached to a radial blade exhauster by way of a high strength fabric hose. See Figure 2.2 for the Phase 2 test arrangement. 


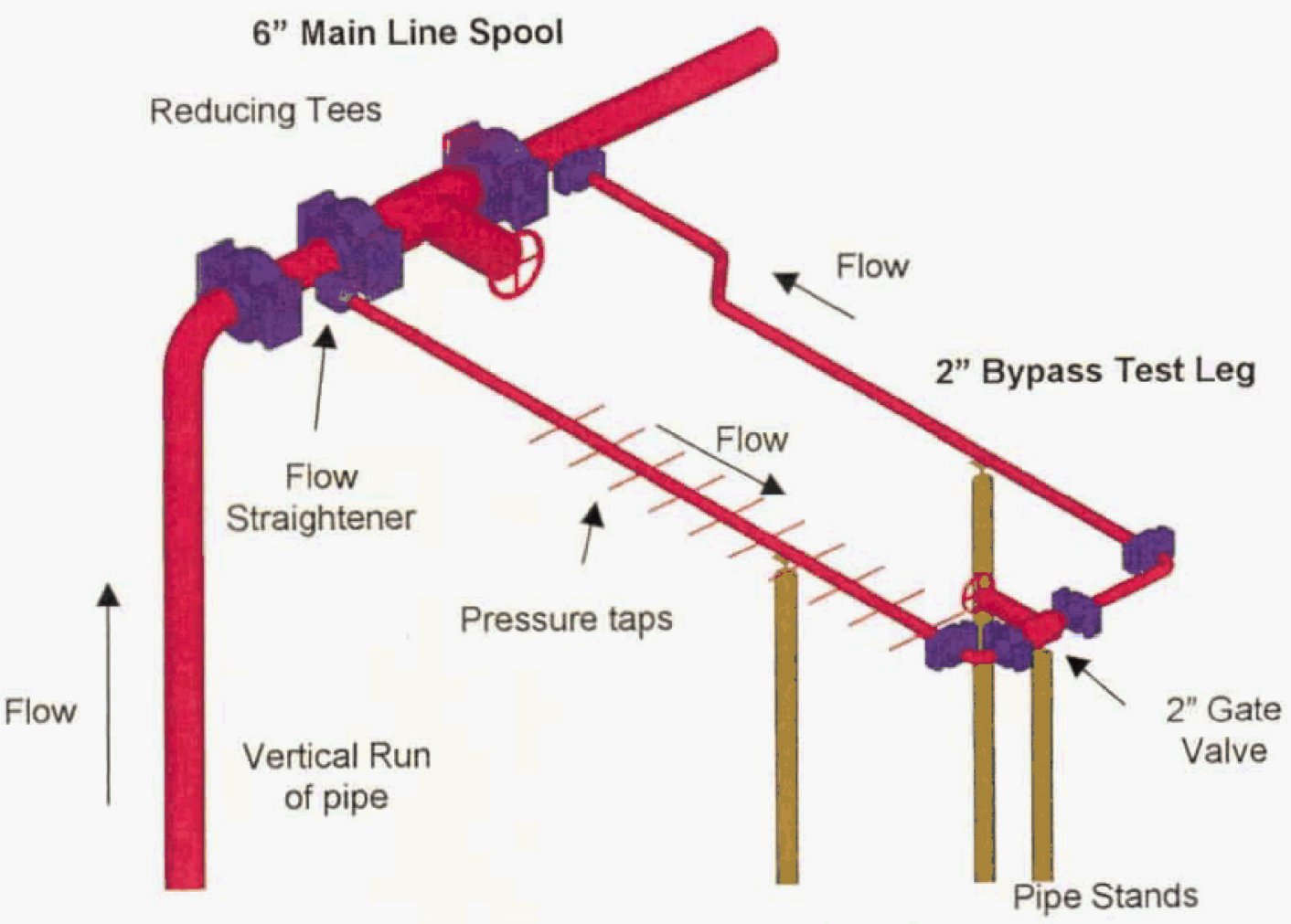

Figure 2.1 Phase 1 test configuration

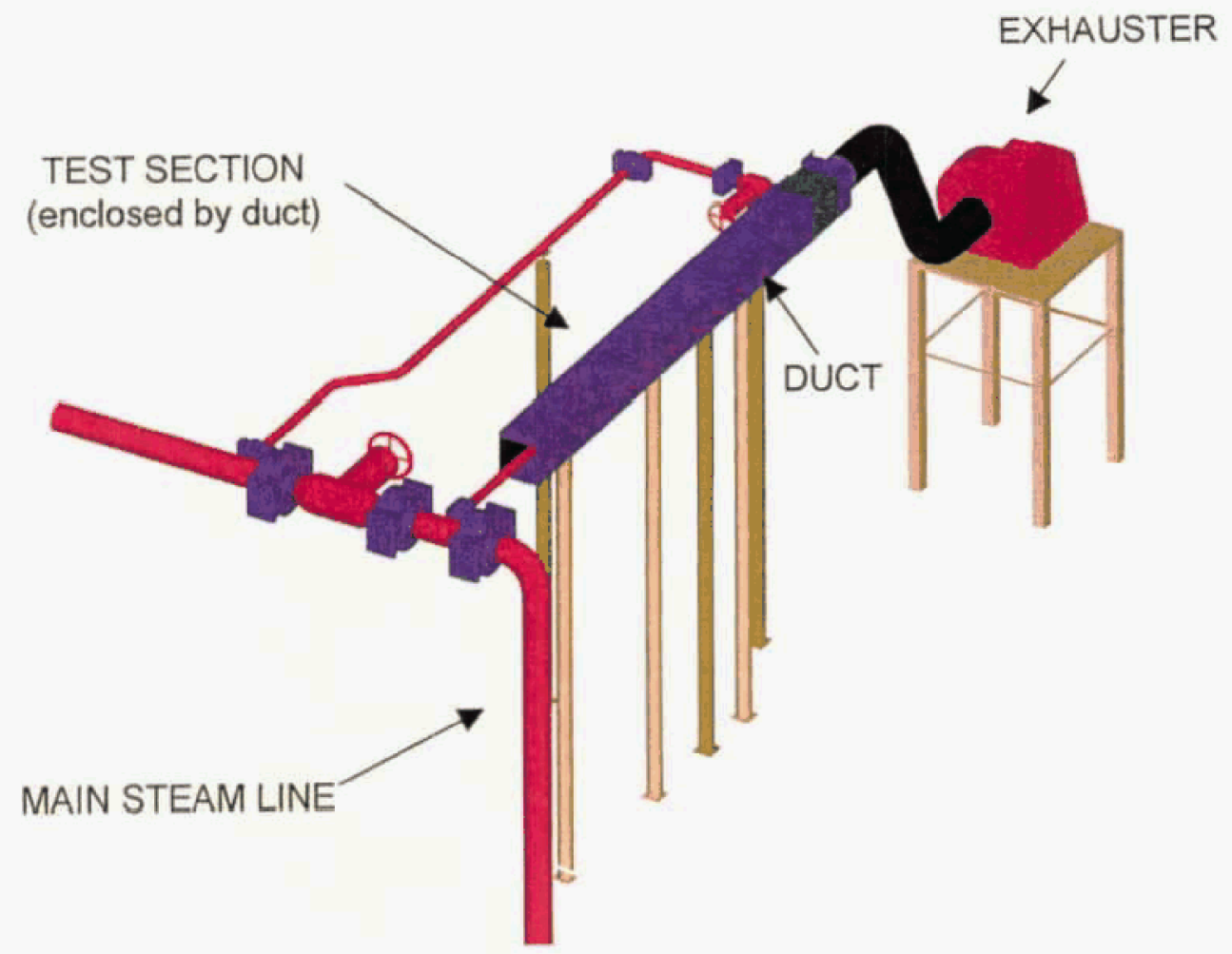

Figure 2.2 Phase 2 test configuration 
At maximum speed, the exhauster provided a maximum air flow rate of 3100 CFM. Air velocity was measured by a pitot probe, which was installed on a straight fiberglass duct that was attached to the exhaust of the fan. Air velocity was integrated over the entire flow area to calculate volumetric flow rate. Thermocouples were placed at the duct entrance and exit to measure inlet and outlet air temperature. Existing thermocouples measured ambient air temperature. The test instrumentation for Phase 2 was calibrated to provide the following accuracies:

- Air temperature

- Air velocity

$\pm 3 \%$

\subsection{DIFFERENTIAL PRESSURE MEASUREMENTS}

Differential pressures were measured between upstream pressure taps $10-4$ and downstream (reference) pressure taps (1-3). These positions are shown by Figure 3.1.

Differential (DP) cells with the following ranges were used.

Table 3.1 DP Cell Ranges

\begin{tabular}{||c|c|c||}
\hline Tap Arrangement & Low Range & High Range \\
\hline \hline Ref Tap / Ref Tap $\left(180^{\circ}\right)$ & 0 to +0.5 psid & - \\
Ref Tap / Tap 4 & 0 to +0.9015 psid & 0 to +2.0 psid \\
Ref Tap / Tap 5 & 0 to +0.9015 psid & 0 to +3.0 psid \\
Ref Tap / Tap 6 & 0 to +0.9015 psid & 0 to +4.0 psid \\
Ref Tap / Tap 7 & 0 to +0.9015 psid & 0 to +5.0 psid \\
Ref Tap / Tap 8 & 0 to +0.9015 psid & 0 to +6.0 psid \\
Ref Tap / Tap 9 & 0 to +0.9015 psid & 0 to +6.0 psid \\
Ref Tap / Tap 10 & 0 to +0.9015 psid & 0 to +7.0 psid \\
\hline
\end{tabular}

Due to the extreme importance of the reference tap, pre-testing was done for several Reynolds number steam flows in order to ensure consistent, and nominal readings. Through pre-testing of the pressure taps, three testing configurations were chosen that provided reliable, consistent readings. These combinations are shown in Table 3.2. Two upstream taps were eliminated ( $4 \mathrm{~N}$ and $4 \mathrm{~S}$ ) from testing due to relatively high deviation and instability.

Table 3.2 Test Configurations

\begin{tabular}{|c|c|c|}
\hline $\begin{array}{c}\text { Reference } \\
\text { Tap }\end{array}$ & Upstream Taps & $\begin{array}{c}\text { Maximum Test } \\
\text { Section Length (LD) }\end{array}$ \\
\hline \hline $1 \mathrm{~N}$ & $5 \mathrm{~N}, 6 \mathrm{~N}, 7 \mathrm{~N}, 8 \mathrm{~N}, 9 \mathrm{~N}, 10 \mathrm{~N}$ & 45 \\
$2 \mathrm{~S}$ & $5 \mathrm{~S}, 6 \mathrm{~S}, 7 \mathrm{~S}, 8 \mathrm{~S}, 9 \mathrm{~S}, 10 \mathrm{~S}$ & 40 \\
$3 \mathrm{~S}$ & $5 \mathrm{~S}, 6 \mathrm{~S}, 7 \mathrm{~S}, 8 \mathrm{~S}, 9 \mathrm{~S}, 10 \mathrm{~S}$ & 35 \\
\hline
\end{tabular}

Pressure drop was measured along the 2" test pipe for steam flow at the pressures and flow rates in Table 3.3. These conditions were established to maximize the Reynolds number range. During phase 1 and phase 2 testing, each condition was repeated using each of the three test configurations. ${ }^{2}$

\footnotetext{
${ }^{2}$ Only one reference tap was used for conditions near the limits of the tested Reynolds number range to avoid reaching the maximum dp allowable at the high end, or avoid reading inaccuracies at the low end
} 
For low Reynolds number steam flow, the limiting condition was the accuracy of the venturi flow meter. For high Reynolds number flow, the limiting condition was the available steam flow from the steam source.

Table 3.3 Test Conditions

\begin{tabular}{|ccc|}
\hline Re & $\begin{array}{c}\text { Mass Velocity } \\
\left(\mathrm{lbm} / \mathrm{hr} \mathrm{ft}^{2}\right)\end{array}$ & $\begin{array}{c}\text { Operating Pressure } \\
(\text { (psig) }\end{array}$ \\
\hline $0.70-0.94 \times 10^{6}$ & $0.17-0.22 \times 10^{6}$ & 220 \\
$0.95-4.00 \times 10^{6}$ & $0.24-1.00 \times 10^{6}$ & 350 \\
$4.30-5.50 \times 10^{6}$ & $1.14-1.45 \times 10^{6}$ & 620 \\
\hline
\end{tabular}

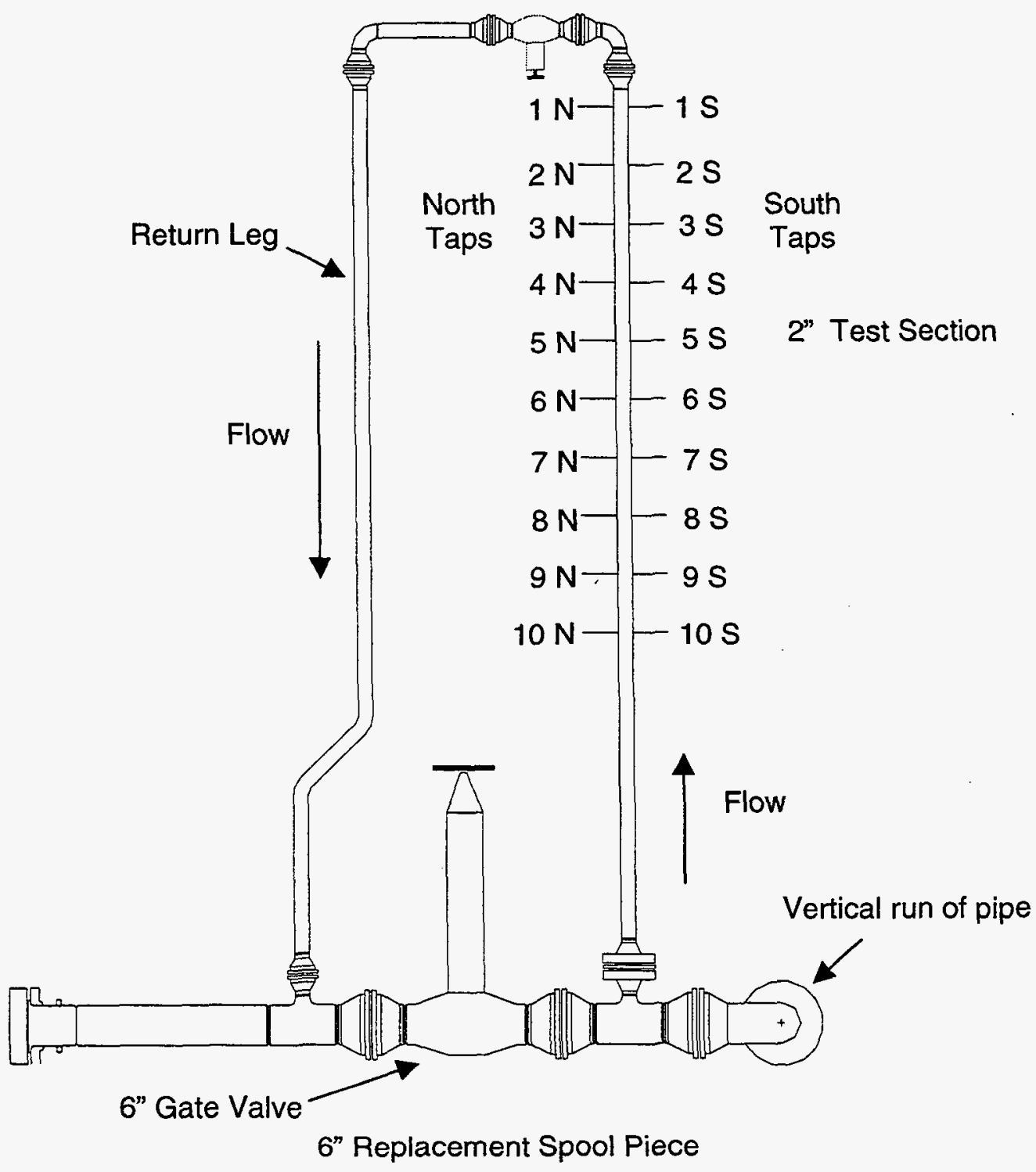

Figure 3.1 Pressure tap arrangement plan 


\subsection{SURFACE ROUGHNESS}

For fully turbulent flow, the friction factor is a function of the Reynolds number and the relative roughness of the pipe.

$$
f=\phi\left(\operatorname{Re}, \frac{\varepsilon}{D}\right)
$$

The relative roughness of the test section can be determined from:

where:

$$
\frac{\varepsilon}{D}=\frac{\pi R a}{D}
$$

Ra = pipe surface roughness average

D $\quad$ p pipe inside diameter

The test section was fabricated from standard commercial rough pipe. The surface measured a roughness average $(R a)$ of about 125 microinches. The surface was measured by an electronic surface roughness tester and by optical comparison to surface roughness standards. The relative roughness of the test section was calculated to be 2.02 $\times 10^{-4}$.

Pipe wall roughness is usually considered to be either uniform or nonuniform in the axial direction. For nonuniform surface roughness, the Moody curve (Figure A.1) can be used to determine friction factor. The Nikuradse curve (Figure A.2) is used for uniform surface roughness. The friction factor curve on the Nikuradse diagram shows the friction factor increasing with Reynolds number for a certain range of Reynolds number. This is due to the laminar sublayer becoming less than the height of the surface asperities.

The laminar sublayer thickness is defined in Reference (a) as:

where:

$$
\delta=4 \sqrt{8}\left[\frac{D}{\operatorname{Re} \sqrt{f}}\right]
$$

$$
\begin{array}{ll}
\delta & =\text { laminar sublayer thickness } \\
D & =\text { pipe inside diameter } \\
\operatorname{Re} & =\text { Reynolds number } \\
f & =\text { friction factor }
\end{array}
$$

For the 125 microinches $(R a)$ roughness, the Reynolds number at which surface asperities begin to impinge on the laminar sublayer would be about $1 \times 10^{6}$. At higher Reynolds number, the roughness protrudes above the laminar sublayer. The asperities enhance the formation of vortices and a general increase in friction factor can occur. The drag reaches some maximum and a flattening of the friction factor curve can be seen.

Both the Moody and the Nikuradse curves were used to compare predicted pressure drop with actual test data. 


\subsection{METHOD TO CALCULATE FRICTION FACTOR UNCERTAINTY}

The measured pressure gradient over the test section was used to define the friction factor:

where:

$$
\left.f=\Delta P /\left(\rho * V^{2} / 2 g_{c}\right)(L / D)\right]
$$

$$
\begin{array}{ll}
\Delta P \quad= & \text { Pressure loss measurement between a downstream reference pressure } \\
& \text { tap and an upstream pressure tap } \\
\rho \quad & =\text { Fluid density } \\
V \quad & =\text { Fluid velocity, where } V=Q /\left(\frac{\pi D^{2}}{4}\right) \\
Q \quad & =\text { Volume flowrate } \\
L \quad & =\text { Distance between pressure measurements } \\
D \quad & =\text { Inside pipe diameter } \\
f \quad=\text { Friction factor }
\end{array}
$$

The total uncertainty of the friction factor measurement was calculated by:

$$
U_{f}=\sqrt{\sigma_{f}^{2}+\beta_{f}^{2}}
$$

where the $\sigma_{f}$ term is primarily based on the uncertainty of the gauges used for the measurements and the second term $\beta_{f}$ term is based on the uncertainty in the physical test assembly conditions. The standard deviation of the friction factor is

$$
\sigma_{f}=\sqrt{\left(\frac{\partial f}{\partial \Delta P} \sigma_{\Delta P}\right)^{2}+\left(\frac{\partial f}{\partial Q} \sigma_{Q}\right)^{2}+\left(\frac{\partial f}{\partial \rho} \sigma_{\rho}\right)^{2}}
$$

The maximum standard deviation of the friction factor was calculated to be $\pm 6 \%$.

Bias uncertainty is the more difficult component to estimate because its component variation sources are not measureable during the testing. The bias uncertainty is intended to bound the variation sources involved in the physical test assembly, not the measurement uncertainties. These include burrs/surface imperfections, local surface roughness effects, flow non-recovery, compressibility effects, and condensation. Since only one test assembly has been built, the bias uncertainty could be considered as the variation that would be found between repeated builds of the same test assembly. The bias uncertainty of the friction factor is

$$
\beta_{f}=\sqrt{\left(\frac{\partial f}{\partial \dot{\Delta} P} \beta_{\Delta P}\right)^{2}+\left(\frac{\partial f}{\partial Q} \beta_{Q}\right)^{2}+\left(\frac{\partial f}{\partial \rho} \beta_{\rho}\right)^{2}+\left(\frac{\partial f}{\partial L} \beta_{L}\right)^{2}+\left(\frac{\partial f}{\partial D} \beta_{D}\right)^{2}}
$$


The bias uncertainty of the friction factor was calculated to be $\pm 8 \%$. Using this approach resulted in a maximum uncertainty $\left(U_{f}\right)$ range of the friction factor measurement to be $\pm 10 \%$ based on a $2 \sigma$ level of confidence.

\subsection{FRICTION FACTORS BASED ON MEASURED PRESSURE GRADIENTS}

The pressure drop in a horizontal straight pipe is the result of two factors: the wall friction force and momentum changes.

$$
\Delta P_{\text {MEASTRED }}=\Delta P_{f}+\Delta P_{m}
$$

The momentum pressure drop is a result of changes to volume flowrate caused by spatial acceleration. Spatial acceleration occurs when the fluid undergoes a change in fluid density. The momentum pressure drop was calculated to be small $(<5 \%)$ and was neglected for this test. The moisture carryover delta across the test section was no greater than $0.7 \%$. Neglecting small momentum effects is conservative because it forces the calculated friction factor to be a small percentage greater than the actual friction factor.

The measured pressure ratio and piping length at each tap was used in a linear regression curve fit to establish the pressure gradient along the pipe. The tap positions have been plotted with respect to distance in piping diameters. The straight-line curve fit results are shown in Figures 6.1 and 6.2. For all test series, good agreement was consistently achieved such that the coefficient of determination $\left(R^{2}\right)$ was greater than 0.98 . A value of 0.98 for $R^{2}$ is said to explain $98 \%$ of the variation in the dependent variable.

For Phase 2 testing, the friction factor was measured over a range of Reynolds number for various fan speeds. Figure 6.3 is a plot of this data in comparison with the Moody and Nikuradse correlations for a relative roughness of $2 \times 10^{-4}$. It is customarily considered that piping roughness effects due to surface texture variation are enveloped by the Moody and Nikuradse correlations. The two classical curves and the test data converge as Reynolds number increases, indicating consistency between the classical methods and the data.

Another step is needed to correlate friction factor directly with moisture carryover. This can be achieved by a heat balance at the steam pipe surface to estimate the mass flowrate of condensation and average flow quality through the steam pipe. 

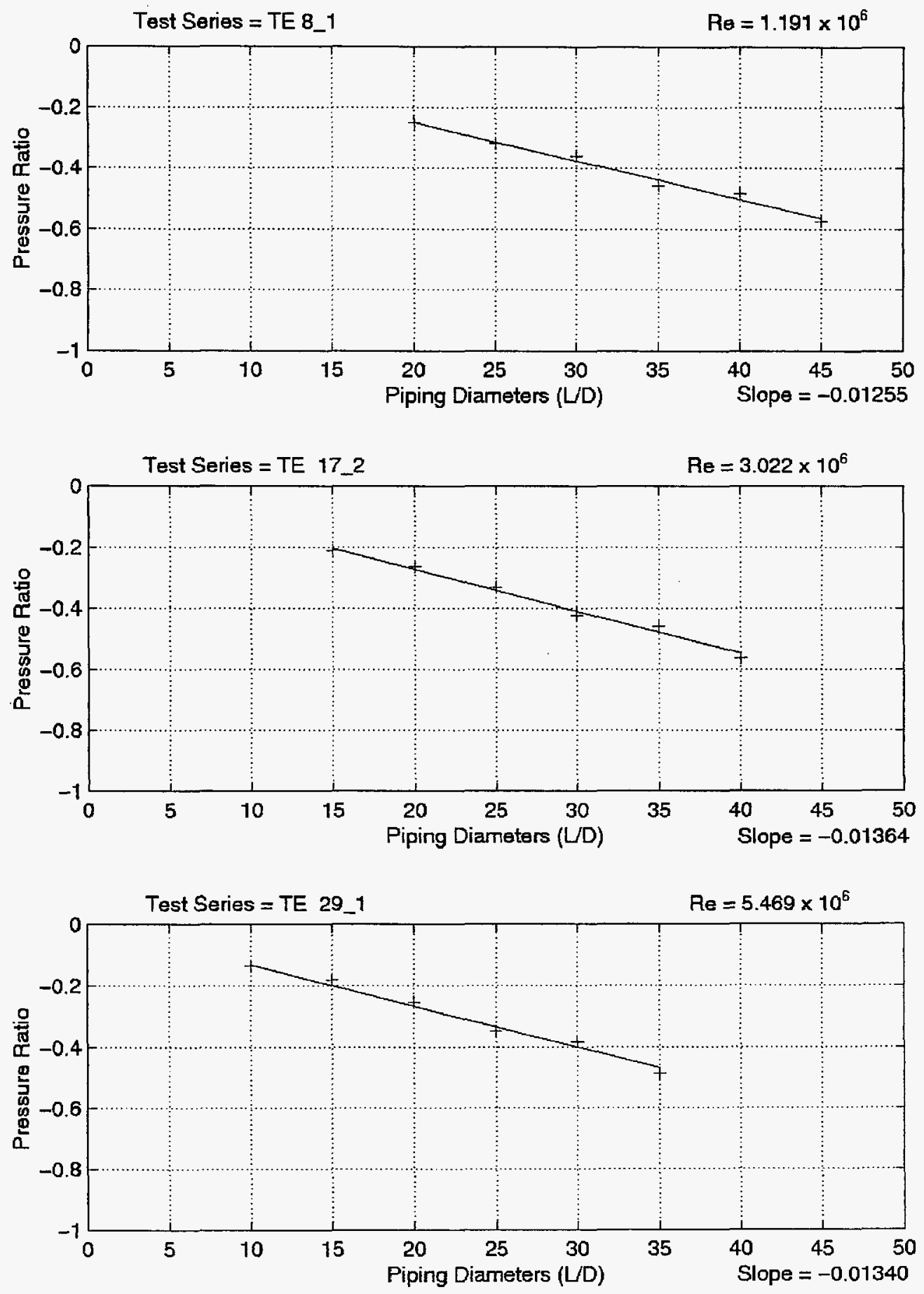

Figure 6.1 Typical Phase 1 pressure gradients 

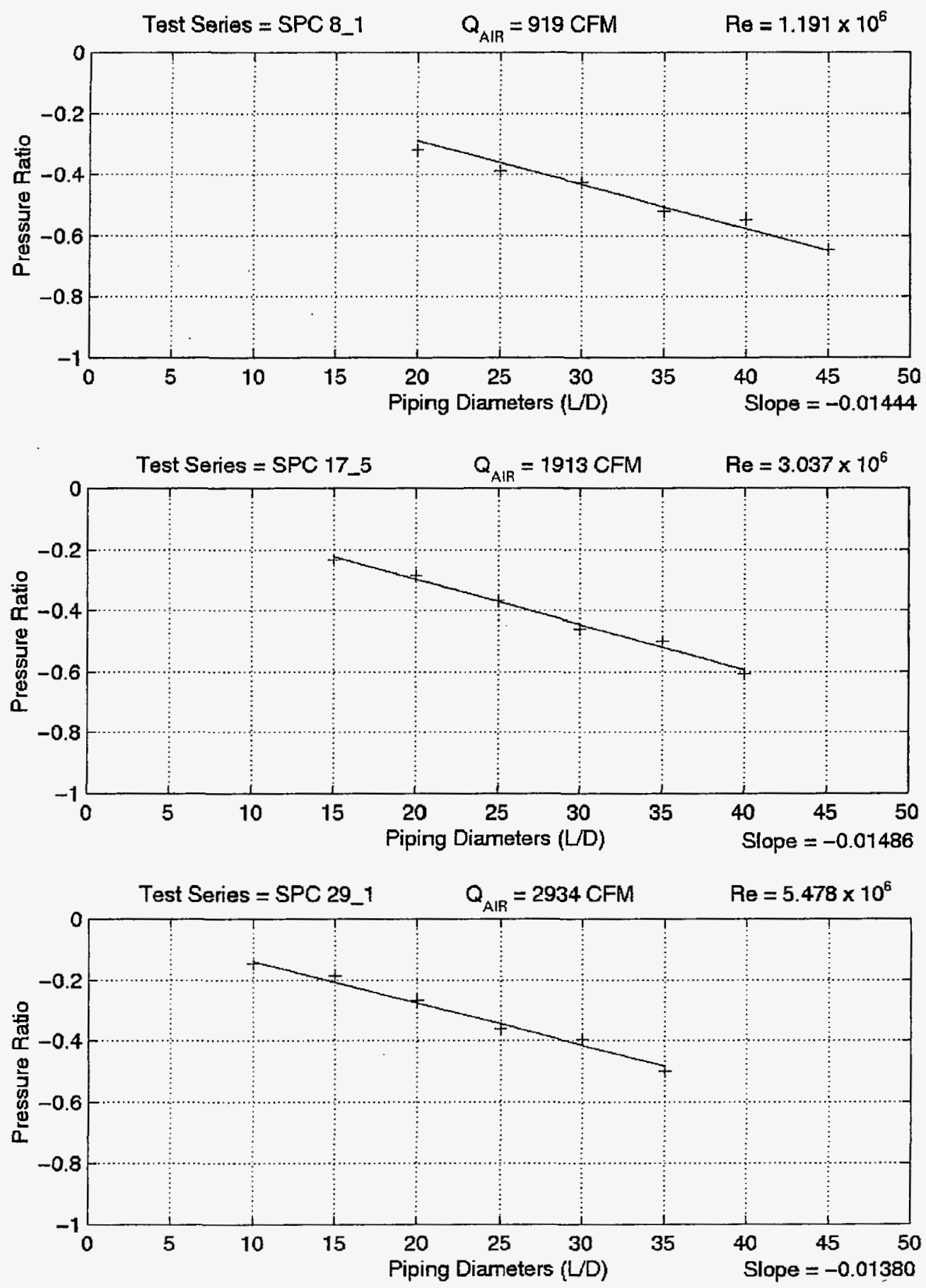

Figure 6.2 Typical Phase 2 pressure gradients 


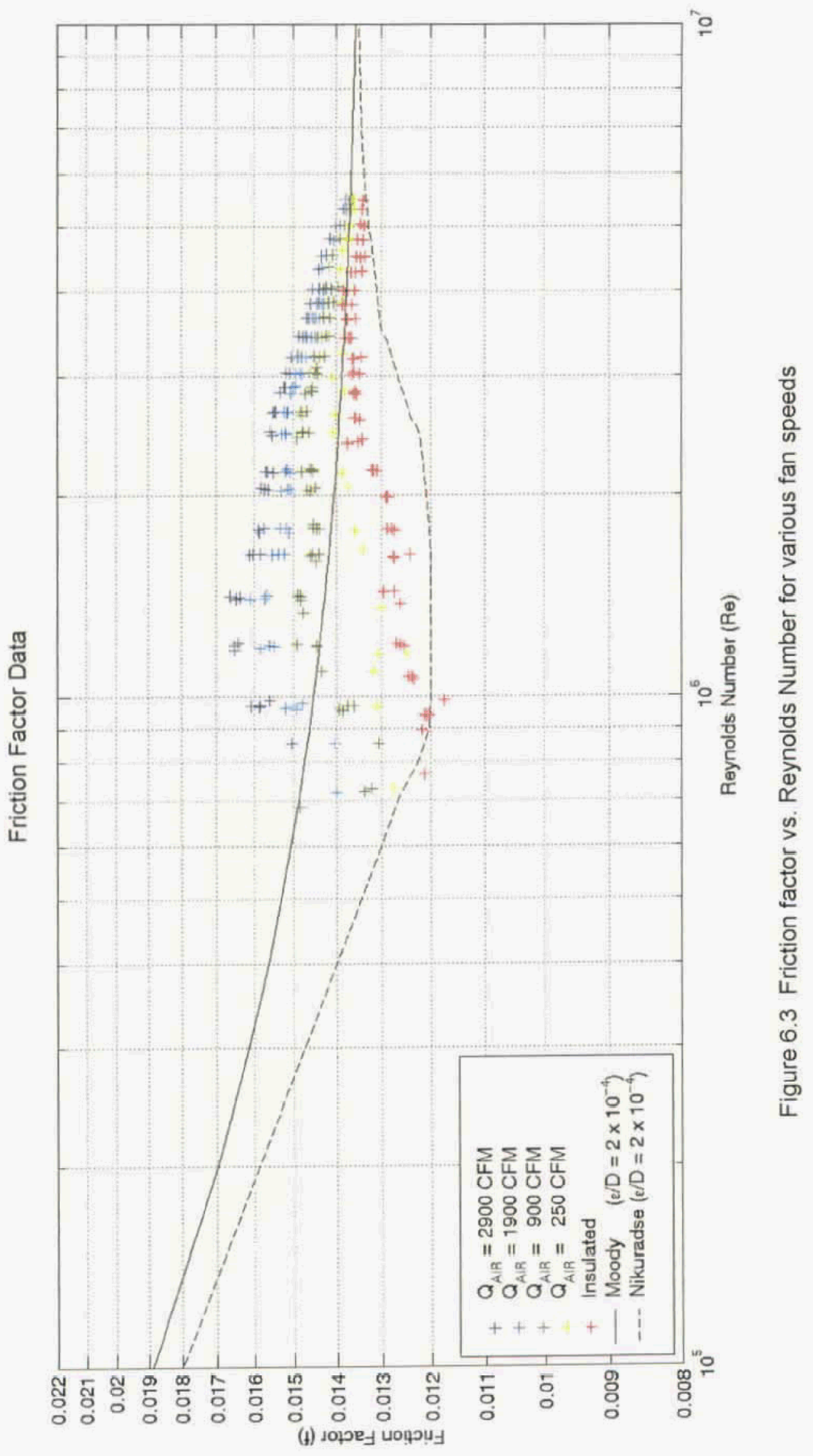




\subsection{STEAM QUALITY BASED ON MEASURED HEAT BALANCE PARAMETERS}

A heat balance on the steam pipe and duct configuration was developed to determine the average quality of the steam flow. All values for mositure formation listed in Table 7.1 and 7.2 were calculated from the heat balance outlined in Appendix B.

The following causes of moisture formation were considered for the entire piping run between the steam source and the exit of the test section:

- Steam source moisture carryover

- Free convection and radiation losses from insulated piping to the ambient air and surroundings (prior to and at the test section)

- Throttling process (acceleration of steam flow from 6" main line to 2 " test section)

- Forced convection losses from bare piping to the cooling air (Phase 2 only)

- Radiative losses from bare piping to the aluminum duct (Phase 2 only)

Phase 1 Testing

The objective of Phase 1 was to minimize moisture formation. Pure steam could not be achieved however, due to the inherent energy losses in the system. Table 7.1 lists the causes of moisture formation for various tested flow conditions for Phase 1.

For steam flow at Reynolds number less than $2.0 \times 10^{6}$, the dominant cause of moisture formation was from convection and radiation losses. For steam flow greater than Reynolds number $2.0 \times 10^{6}$, the dominant cause of moisture formation was from kinetic energy losses at the flow restriction. At the maximum Reynolds number tested, the total moisture was estimated to be $0.429 \%$ of the steam flow.

Table 7.1 Causes of Moisture Formation (Phase 1)

\begin{tabular}{|c|c|c|}
\hline $\begin{array}{c}\text { Reynolds } \\
\text { Number }\end{array}$ & $\begin{array}{c}\text { Radiation + Convection } \\
\text { Losses (\%) }\end{array}$ & $\begin{array}{c}\text { Kinetic Energy } \\
\text { Losses (\%) }\end{array}$ \\
\hline $0.94 \times 10^{6}$ & 0.145 & 0.005 \\
$2.0 \times 10^{6}$ & 0.069 & 0.057 \\
$3.0 \times 10^{6}$ & 0.045 & 0.142 \\
$4.0 \times 10^{6}$ & 0.035 & 0.262 \\
$4.8 \times 10^{6}$ & 0.035 & 0.282 \\
$5.5 \times 10^{6}$ & 0.030 & 0.369 \\
\hline
\end{tabular}

Phase 2 Testing

The objective of Phase 2 testing was to add additional moisture to the steam flow by increasing convection heat losses. Steam flow and pressure were repeated as fan speed was varied to control moisture.

For Phase 2 testing, the quality of the steam at the exit of the test section was calculated by way of a heat balance between the cooling air and the steam pipe. Air flowrate and inlet temperature were measured and entered into the heat balance model. Using these 
measurements, the convection and radiation losses at the steam pipe surface were calculated. The average moisture carryover over the entire test section was readily calculated using the steam quality at the inlet and outlet of the test pipe.

From the heat balance, the heat flux from the steam pipe was calculated. Moisture formation is a function of heat loss and the heat of vaporization for the steam at the saturation pressure.

Moisture increase from heat loss is defined as

where:

$$
\dot{m}_{C O N D}=\frac{q_{T O T}}{h_{f g}}
$$

$$
\begin{aligned}
& q_{T O T}=\begin{array}{l}
\text { heat transfer out of the steam pipe including radiation and convection } \\
\text { losses (from heat balance) }
\end{array} \\
& h_{f g}=\text { latent heat of vaporization (from saturated steam properties) } \\
& \dot{m}_{C O N D}=\text { mass flowrate of condensate }
\end{aligned}
$$

The moisture carryover (MCO) is expressed as

where:

$$
M C O=\frac{\dot{m}_{C O N D}}{\dot{m}_{S T E A M}}
$$

$$
\dot{m}_{\text {STEAM }}=\text { mass flowrate of steam }
$$

Table 7.2 shows the modes of moisture addition for a typical fan speed of 2934 CFM. The fan was less effective at generating moisture for higher Reynolds number flow. Moisture increase due to convection losses was significantly higher for lower Reynolds number flow.

Table 7.2 Causes of Moisture (Fan Speed 2934 CFM)

\begin{tabular}{|c|c|c|}
\hline $\begin{array}{c}\text { Reynolds } \\
\text { Number }\end{array}$ & $\begin{array}{c}\text { Radiation + Convection } \\
\text { Losses (\%) }\end{array}$ & $\begin{array}{c}\text { Kinetic Energy } \\
\text { Losses (\%) }\end{array}$ \\
\hline $0.94 \times 10^{6}$ & 0.768 & 0.005 \\
$2.0 \times 10^{6}$ & 0.365 & 0.057 \\
$3.0 \times 10^{6}$ & 0.242 & 0.142 \\
$4.0 \times 10^{6}$ & 0.186 & 0.262 \\
$4.7 \times 10^{6}$ & 0.174 & 0.282 \\
$5.5 \times 10^{6}$ & 0.141 & 0.369 \\
\hline
\end{tabular}

Figure 7.1 is a plot of the friction factor versus the Reynolds number for the range of flow quality measured. Once again this data is compared to the Moody and Nikuradse curves for a relative roughness of $2 \times 10^{-4}$. Fan speeds have been replaced with estimated flow quality. Moisture bands can be clearly seen on the plot. The spacing between moisture bands decreases substantially as Reynolds number increases. Friction factor data at moisture content less than $0.25 \%$ are enveloped by the Moody and Nikuradse correlations showing good agreement for near dry data. 


\section{Friction Factor Data}

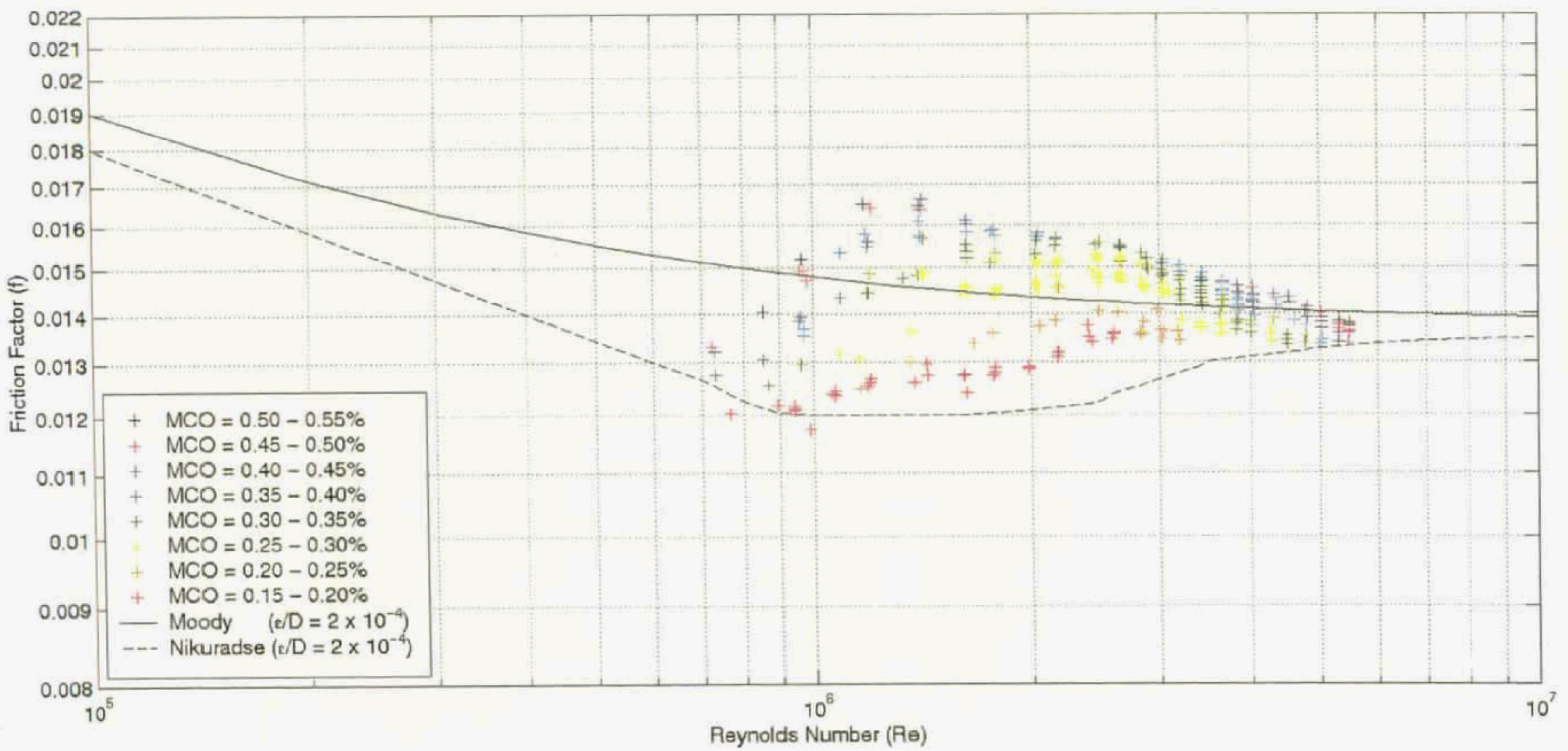

Figure 7.1 Friction factor vs. Reynolds number at estimated moisture levels 


\subsection{Two-Phase Multiplier Correlations}

Analysis of the pressure drop data as shown in Figure 7.1 has led to the development of a correlation between friction factor, Reynolds number, and flow quality over a Reynolds number range of $0.9 \times 10^{6}-5.5 \times 10^{6}$. This correlation in the form of a multiplier is a correction on the classical single-phase friction factor.

Phase 1 data represents the baseline for which all Phase 2 data was compared. As the insulation was removed and fan speed increased over the test pipe, the friction factor increased. For all Reynolds numbers tested, the friction factor increased linearly as flow quality decreased, as shown in Figure 8.1.

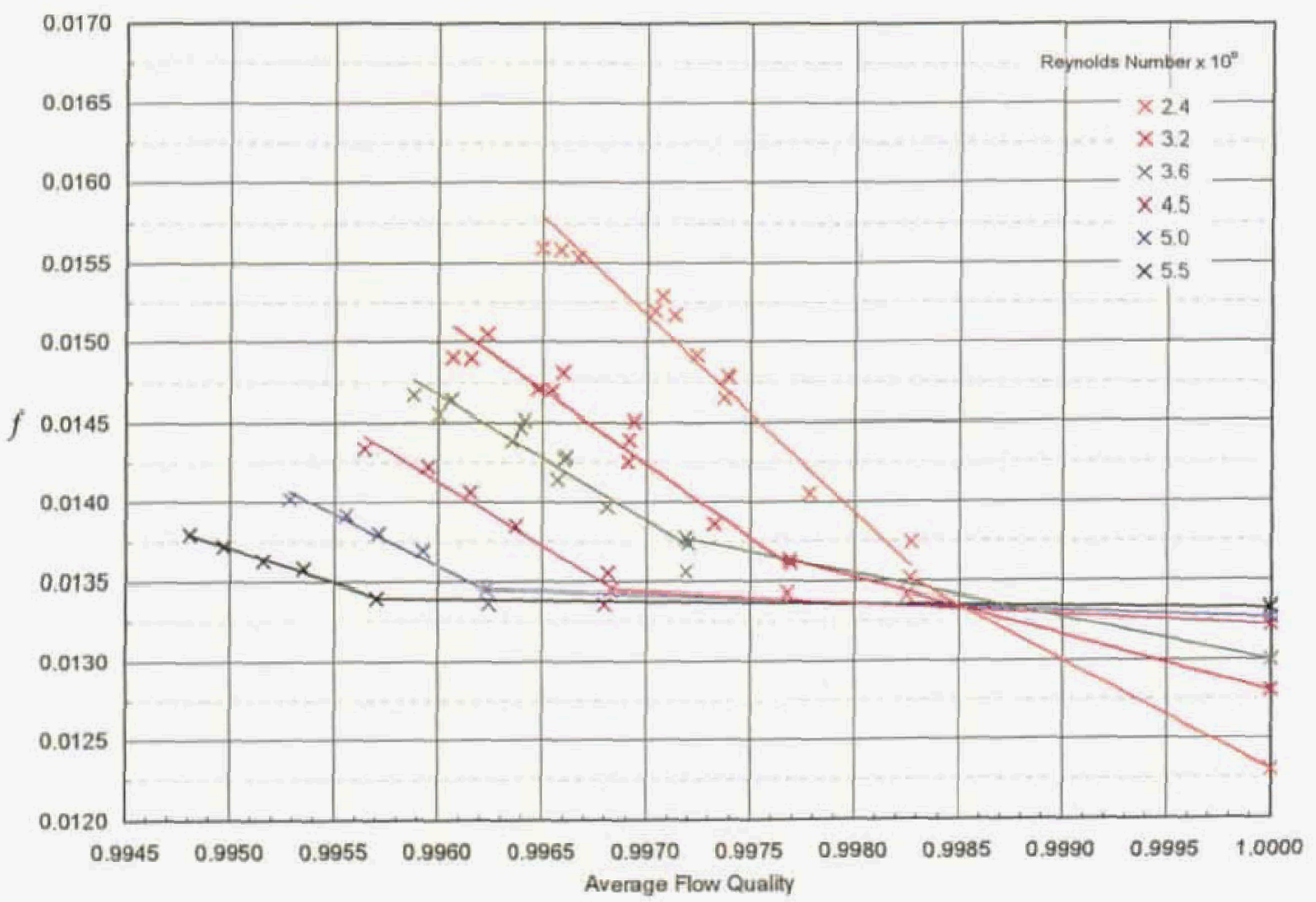

Figure 8.1 Friction factor vs. flow quality

Using linear regression analysis, the test data was fit to a straight line over the tested flow quality range. For steam flow quality greater than the tested range (as flow quality approaches one), a straight line was fit between the test data and the predicted singlephase friction factor. This two line method is used to model the complex relationship between the friction factor and the flow quality for various Reynolds number. Using this approach, a multiplier can be defined as

$$
\text { Two }- \text { Phase Multiplier }=\frac{f_{\text {TWO-PHASE }}}{f_{\text {SINGLE-PHASE }}}
$$

where:

$$
\begin{array}{ll}
f_{\text {TWO-PHASE }} & =\text { measured friction factor } \\
f_{\text {SINGLB-PHASE }} & =\text { predicted single-phase friction factor (Nikuradse correlation) }
\end{array}
$$


The two-phase multiplier is a quantitative value which describes the impact of moisture content on pressure drop such that

$$
\Delta p=\left(f_{\text {SINGLE-PHASE }} L / D\right) *\left(\rho V^{2} / 2\right) * \text { Two - Phase Multiplier }
$$

Using the two line method as shown in Figure 8.1, the two-phase multiplier can be plotted against Reynolds number for various moisture levels as shown in Figure 8.2. The twophase multiplier reaches a maximum at $\operatorname{Re} \sim 2.0 \times 10^{6}$, and decreases exponentially to one as Reynolds number increases. This model can be used on a case basis for estimating the expected pressure drop increase for high quality steam flow at a given Reynolds number and moisture carryover. The model also reveals that the impact of moisture formation on pressure drop significantly decreases as Reynolds number increases.

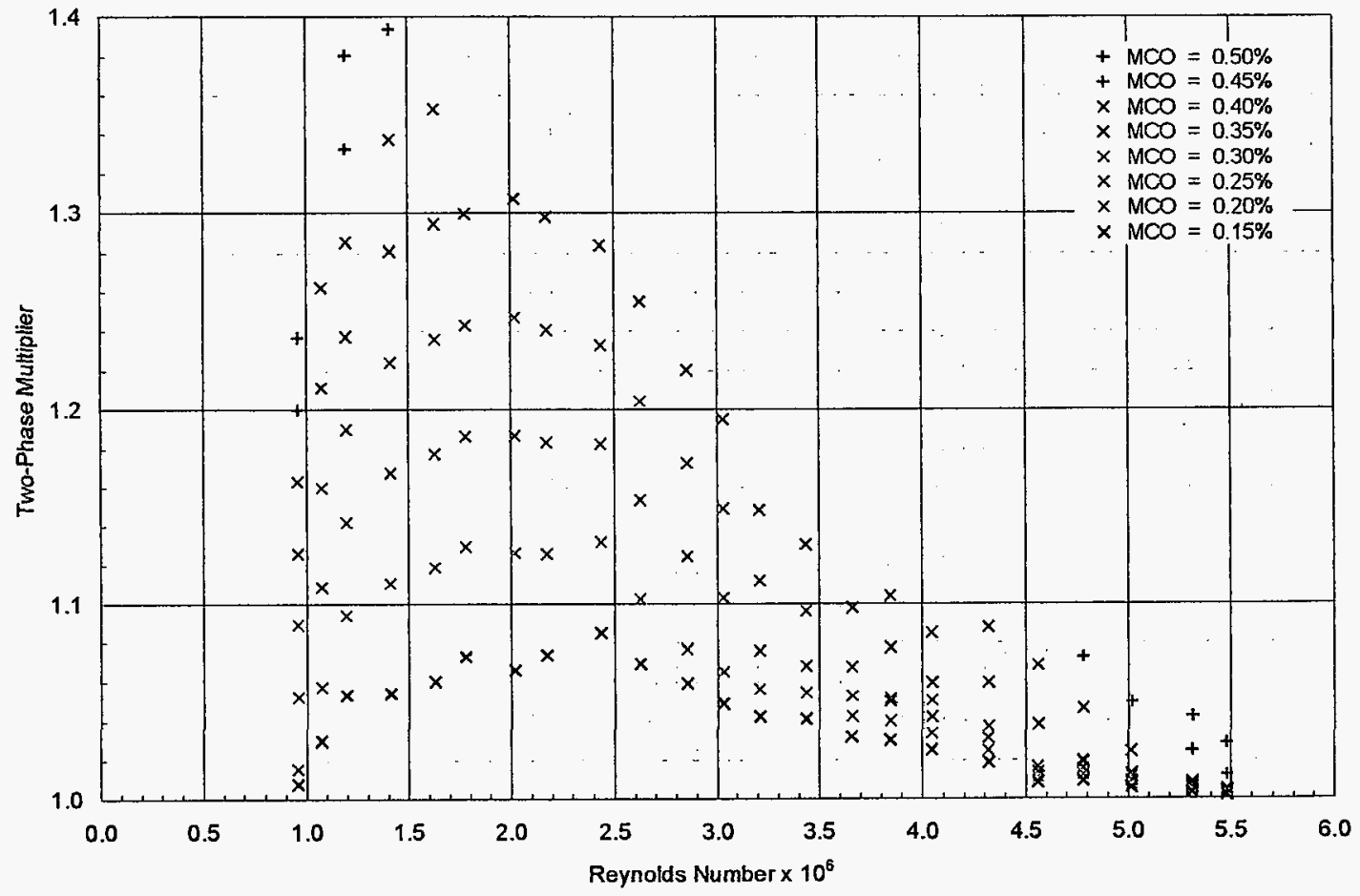

Figure 8.2 Two-phase multiplier curves for various moisture content

The uncertainty of the two-phase multiplier can only be approximated and is a function of the accuracy of the energy balance used to calculate flow quality, the total uncertainty of the friction factor measurements, the accuracy of the predicted single-phase friction factor, and the number of acquired data points. To determine the uncertainty of the two-phase multiplier, the uncertainty of the fitted slope of the straight line fit shown in Figure 8.1 was calculated for each test series. In order to mitigate the wide variations in the slope uncertainties due to the differing ranges of measurement and number of data points, the average slope uncertainty for all the test series was calculated to be $\pm 18 \%$. This value is a best estimate of the overall uncertainty of the two-phase multiplier. If required, a more rigorous statistical analysis and further testing would be required to provide a better uncertainty estimate. 


\subsection{SUMMARY AND CONCLUSIONS}

The steam piping bench test data can be used to estimate the effect of moisture on irrecoverable pressure drop for high Reynolds number, high quality steam flow. A method to quantify the effect of condensation for high quality steam at high flow rates has been developed in the form of a two-phase multiplier, which can be used to correct for the pressure drop due to moisture formation. Test data showed that two-phase flow effects on pressure drop decrease significantly with Reynolds number. 


\subsection{REFERENCES}

(a) J.W. Daily and D.F. Harleman, "Fluid Dynamics," Addison-Wesley, pp. 267-272, 1966.

(b) "Flow of Fluids Through Valves, Fittings and Pipe," Technical Paper No. 410, p. A24 Crane Co., 1985.

(c) I.E. Idelchik, "Handbook of Hydraulic Resistance," p.111 Hemisphere, 1986.

(d) Incropera, F.P. and DeWitt, D.P., "Fundamentals of Heat and Mass Transfer," $4^{\text {th }}$ Ed. , p. 445 John Wiley and Sons, 1996.

(e) Incropera, F.P. and DeWitt, D.P., "Fundamentals of Heat and Mass Transfer," $4^{\text {th }}$ Ed. , p. 738 John Wiley and Sons, 1996. 
Appendix A: Friction Factor Correlations

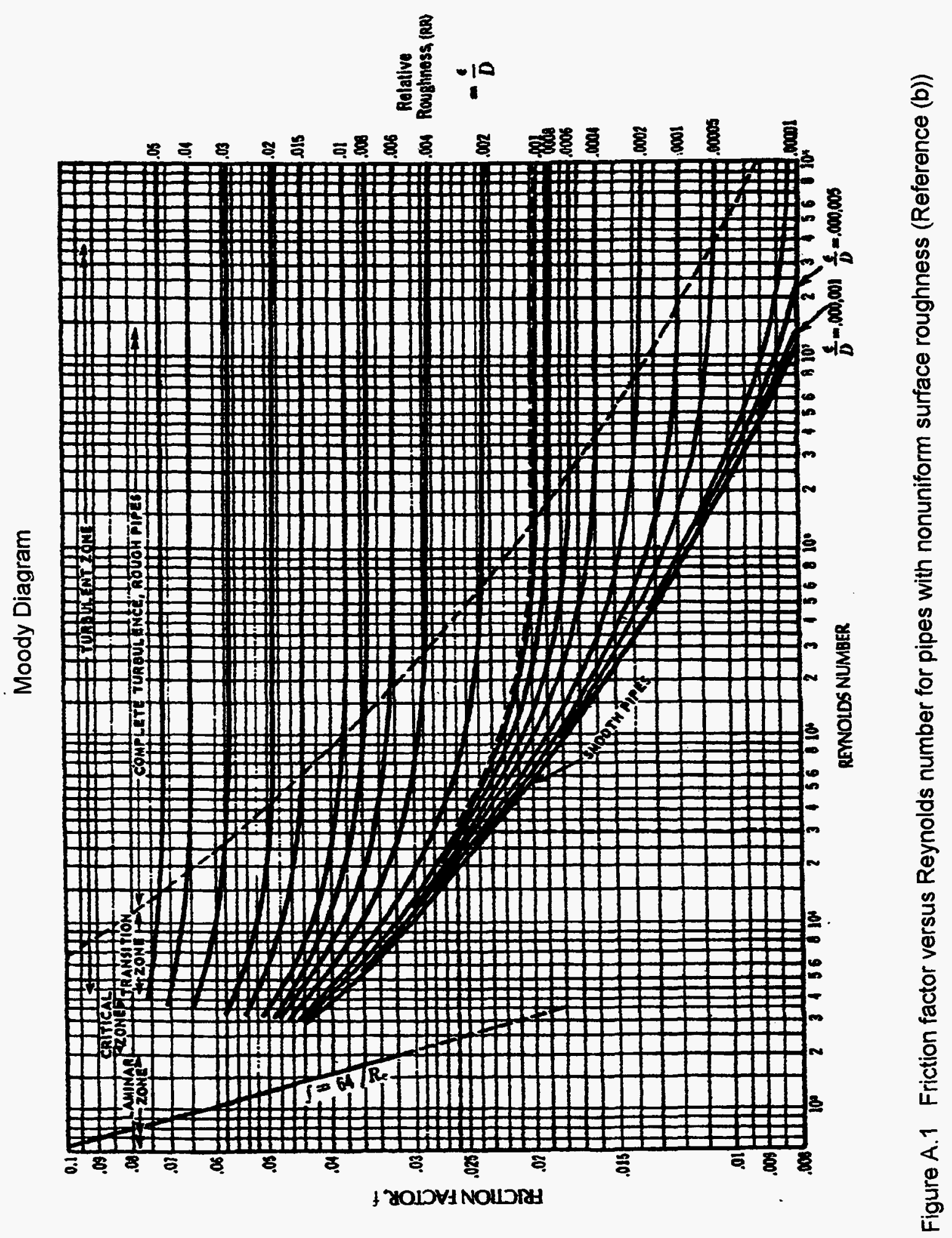


Nikuradse Diagram

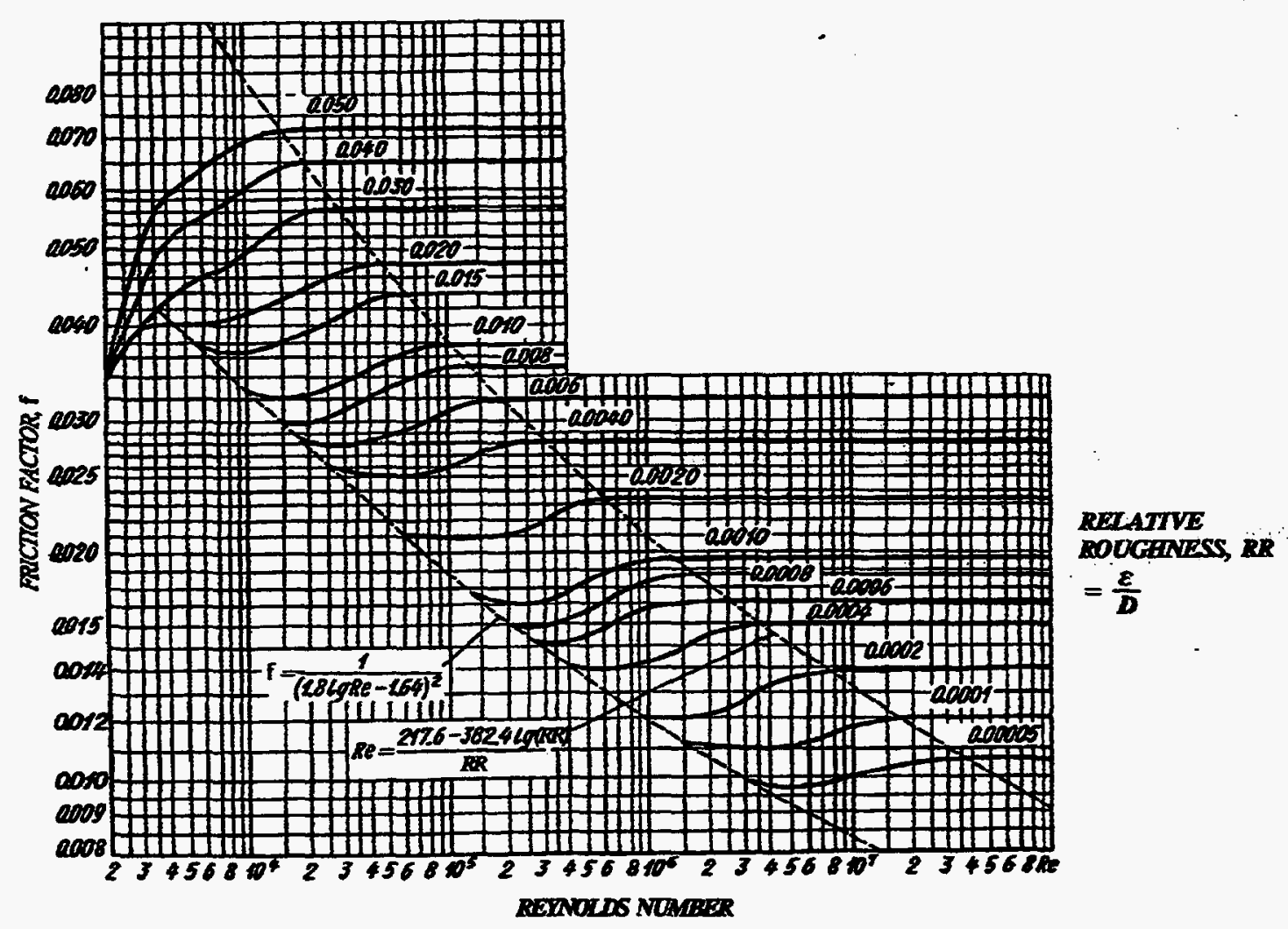

Figure A.2 Friction factor versus Reynolds number for pipes with uniform surface roughness (Reference (c)) 


\section{Appendix B: Heat Balance Model}

\section{Throttling Process}

The flow restriction at the 2 " test section followed by the flow straightener was modeled as a steady state steady flow insulated nozzle (the reducing tee and flow straightener were insulated with 2 inch thick hot caps for Phase 1 and Phase 2 testing). From the first law of thermodynamics, the exit steam enthalpy was:

$$
h_{e}=h_{i}+\frac{V_{i}^{2}-V_{e}^{2}}{2}
$$

where:

$$
\begin{array}{ll}
h_{i} & =\text { inlet enthalpy } \\
V_{i} & =\text { velocity through } 6^{\prime \prime} \text { main line } \\
V_{e} & =\text { velocity through } 2 \text { " test section }
\end{array}
$$

A velocity increase from the inlet to the outlet resulted in a decrease in enthalpy. Because of the significant pressure drop due to the flow restriction caused by the 2 " test section and flow straightener, $h_{e}$ was less than $h_{g}$ for all test series. Therefore the steam remained at saturation, a phase change occurred, and the flow quality must be calculated.

The state of the fluid is defined by the pressure and enthalpy, thus the quality at the exit was determined:

$$
\chi_{e}=\frac{h_{e}-h_{f}\left(P_{S A T}\right)}{h_{f g}\left(P_{S A T}\right)}
$$

where:

$h_{f g} \quad=$ latent heat of vaporization at test section pressure

$h_{f} \quad=$ enthalpy of the fluid at test section pressure

\section{Heat Balance For Phase 2}

The cooling air can be modeled as a concentric tube annulus internal flow problem with heat transfer occurring at both surfaces: Surface 1 is the steam pipe and air interface, Surface 2 is the air and duct interface.

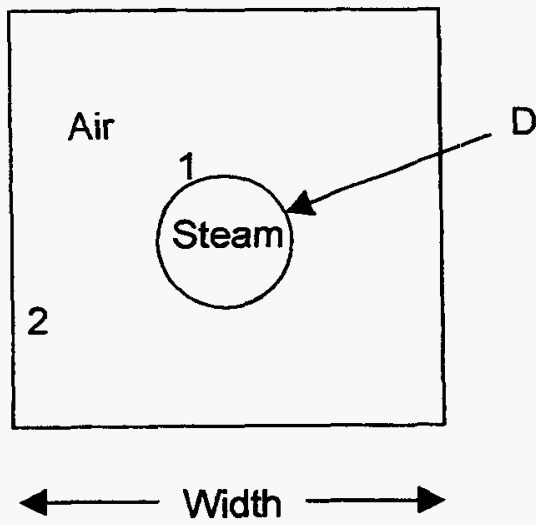


The total heat loss out of the pipe is:

$$
q_{T O T}=q_{C O N Y}+q_{R A D}
$$

To determine the heat loss due to convection:

where:

$$
q_{\mathrm{CONV}}=h_{\mathrm{CONV}} A \Delta T_{L M}
$$

$h_{\mathrm{CONV}}=$ convection coefficient

$A \quad=$ steam pipe surface area

$\Delta T_{L M}=\log$ mean temperature difference between steam and air

where:

$$
\Delta T_{L M}=\frac{\Delta T_{o}-\Delta T_{j}}{\ln \left(\Delta T_{o} / \Delta T_{i}\right)}
$$

$$
\begin{array}{ll}
\Delta T_{o} & =T_{\text {STEAM }}-T_{\text {AIR, OUTLET }} \\
\Delta T_{i} & =T_{\text {STEAM }}-T_{\text {AIR, INLET }}
\end{array}
$$

Because the air temperature increase over the length of the duct is relatively small, the log mean temperature is

$$
\Delta T_{L M} \cong T_{S T E A M}-T_{A I R, A V E}
$$

The convection coefficient is calculated:

where:

$$
h_{\text {conv }}=\frac{k * N u_{D}}{D_{A N N L}}
$$

$N u_{D} \quad=$ Nusselt Number

$D_{A N N L L}=$ hydraulic diameter of annulus

$k=$ thermal conductivity of air at operating temperature

where:

$$
D_{A N N L L}=\frac{4 * A_{c}}{P}
$$

$A_{c} \quad=$ cross sectional area of air flow region

$P \quad=$ perimeter of wetted flow region

The Nusselt number for turbulent intemal flow over a smooth pipe:

$$
N u_{D}=\frac{(f / 8) \operatorname{Re}_{D} \operatorname{Pr}}{1.07+12.7(f / 8)^{1 / 2}\left(\operatorname{Pr}^{2 / 3}-1\right)} \quad(\text { Reference }(\mathrm{d}))
$$

where:

$\operatorname{Pr} \quad=$ Prandtl number for air ( 0.72)

$f \quad=$ friction factor, outside surface of steam pipe (modeled as smooth pipe) 
where:

$$
\operatorname{Re}_{D}=\frac{\rho V D_{A N N U L}}{\mu}
$$

$$
\begin{array}{ll}
\rho & =\text { density of air } \\
V & =\text { velocity of air } \\
\mu & =\text { viscosity of air }
\end{array}
$$

This correlation is valid for $0.5<\operatorname{Pr}<2,000 ; 10,000<\operatorname{Re}_{D}<5,000,000$

For smaller Reynolds number flow,

$$
N u_{D}=\frac{(f / 8)\left(\operatorname{Re}_{D}-1000\right)}{1+12.7(f / 8)^{1 / 2}\left(\operatorname{Pr}^{2 / 3}-1\right)}(\text { Reference }(\mathrm{d}))
$$

This correlation is valid for $0.5<\operatorname{Pr}<2,000 ; \operatorname{Re}_{D}>3,000$

To determine the heat loss due to radiation, assume the air duct and steam pipe configuration is an enclosure between two diffuse, gray surfaces.

For a two surface enclosure, the radiation heat transfer between a hot enclosed inner surface and a cold outer surface is expressed as:

where:

$$
q_{\text {rad }}=\frac{\sigma A_{H O T}\left(T_{H O T}^{4}-T_{C O L D}^{4}\right)}{\frac{1}{\varepsilon_{H O T}}+\frac{A_{H O T}}{A_{C O L D}}\left(\frac{1}{\varepsilon_{C O L D}}-1\right)}(\text { Reference }(\mathrm{e}))
$$

$$
\begin{array}{ll}
\sigma & =\text { Boltzmann's Constant }\left(17.3 \times 10^{-10}\right) \\
A_{H O T} & =\text { surface area of hot body (steam pipe) } \\
A_{C O L D} & =\text { surface area of cold body (duct) } \\
\varepsilon_{H O T} & =\text { emissivity of hot body (carbon steel pipe } \sim 0.8) \\
\varepsilon_{C O L D} & =\text { emissivity of cold body (aluminum duct } \sim 0.2) \\
T_{H O T} & =\text { surface temperature of hot body }\left(\sim T_{S A T}\right) \\
T_{C O L D} & =\text { inside surface temperature of duct }\left(\sim T_{A I R, A V E}\right)
\end{array}
$$

Conduction through the pipe wall and through the condensate film is neglected because resistance is small compared to convection and radiation resistances. 
Appendix C: Index of Data Runs
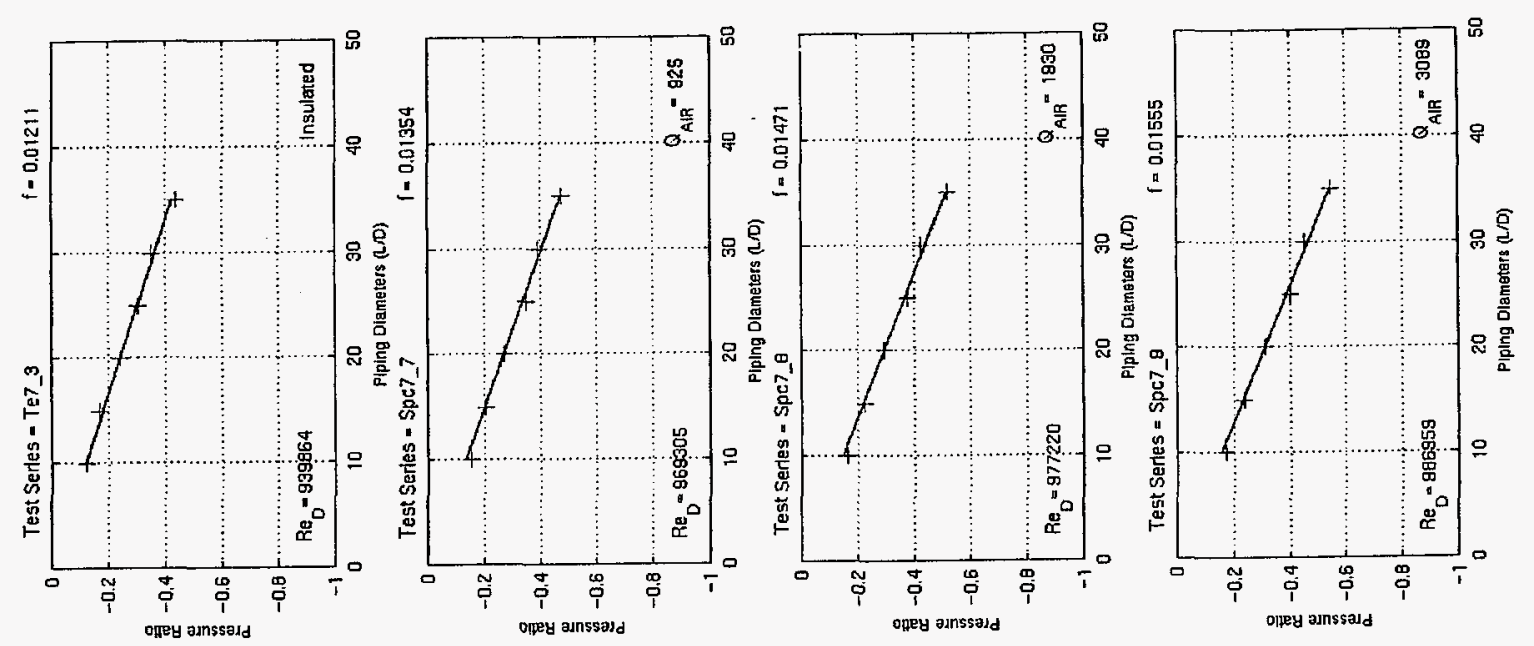

$\stackrel{0}{x}$
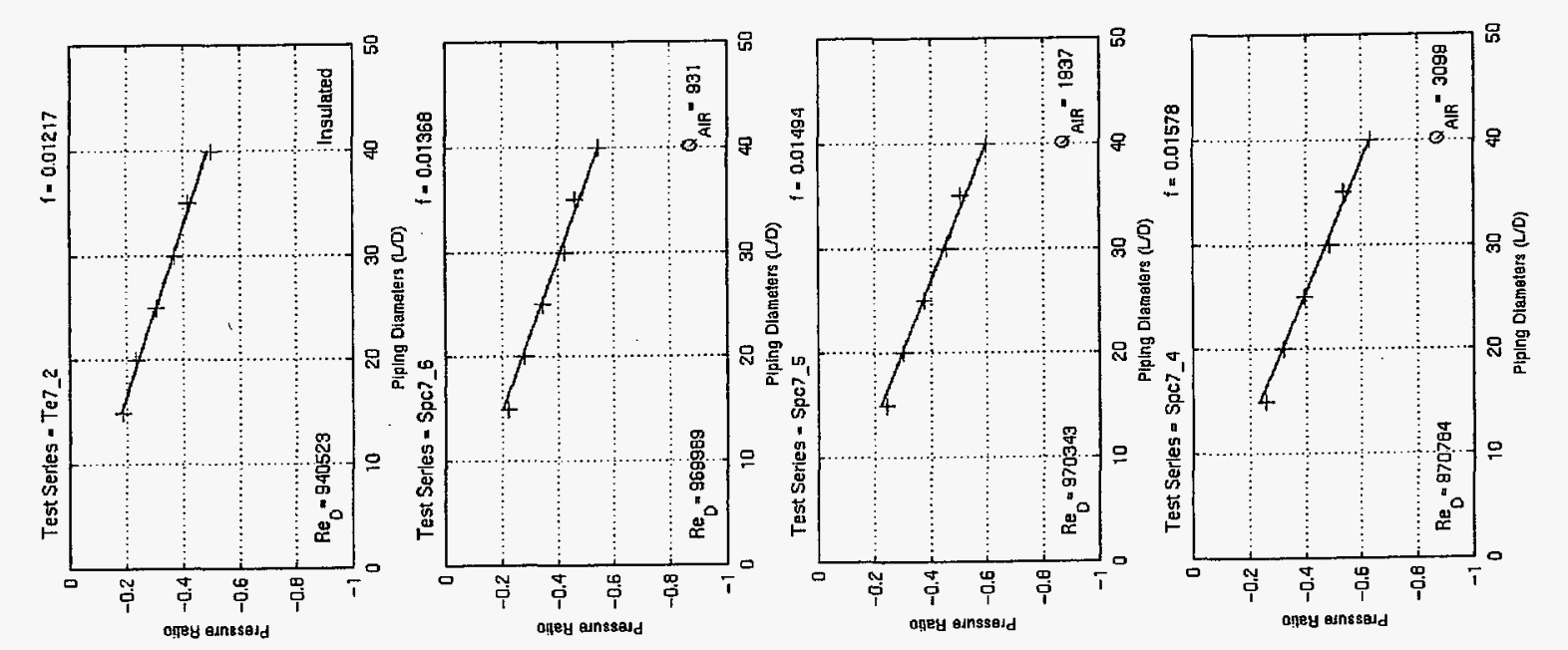

œ
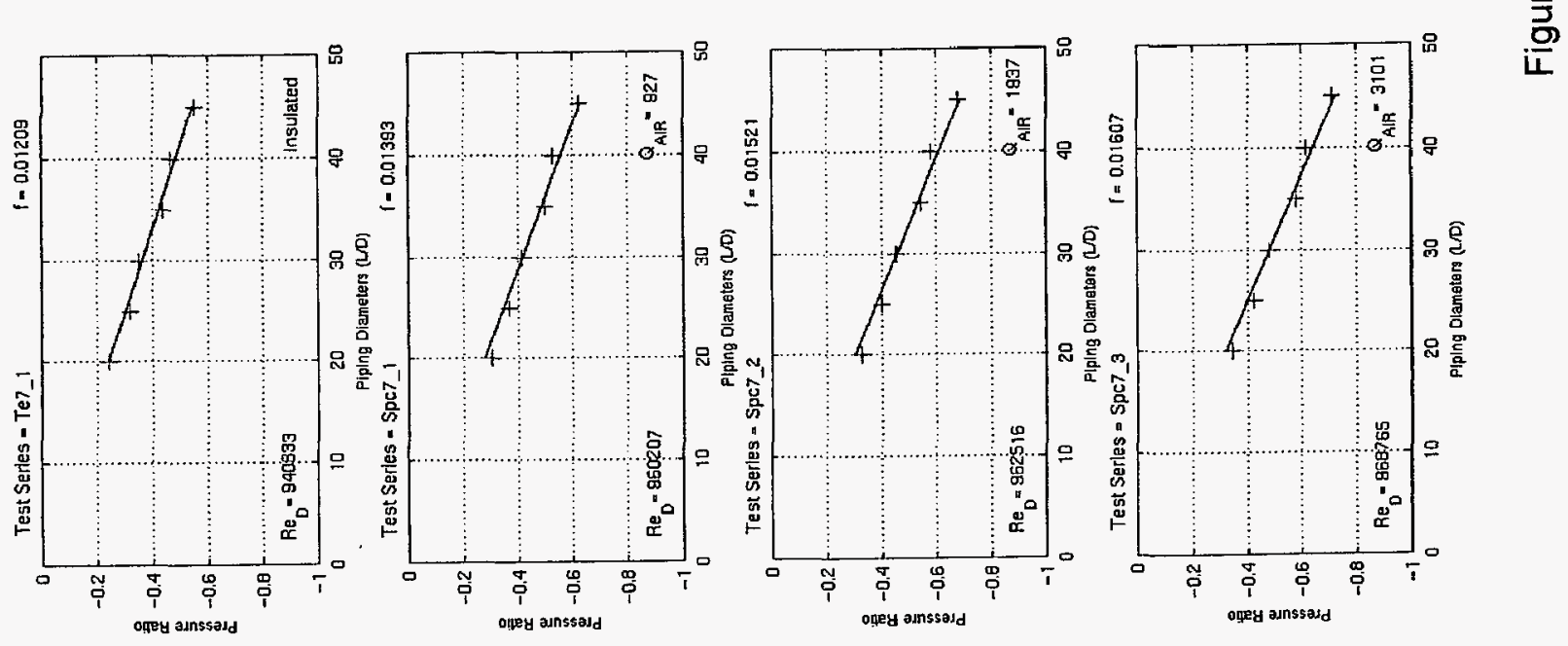


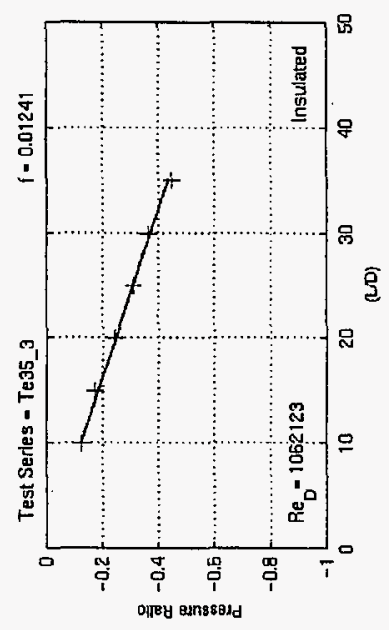

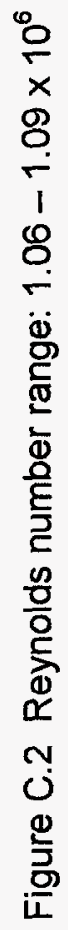
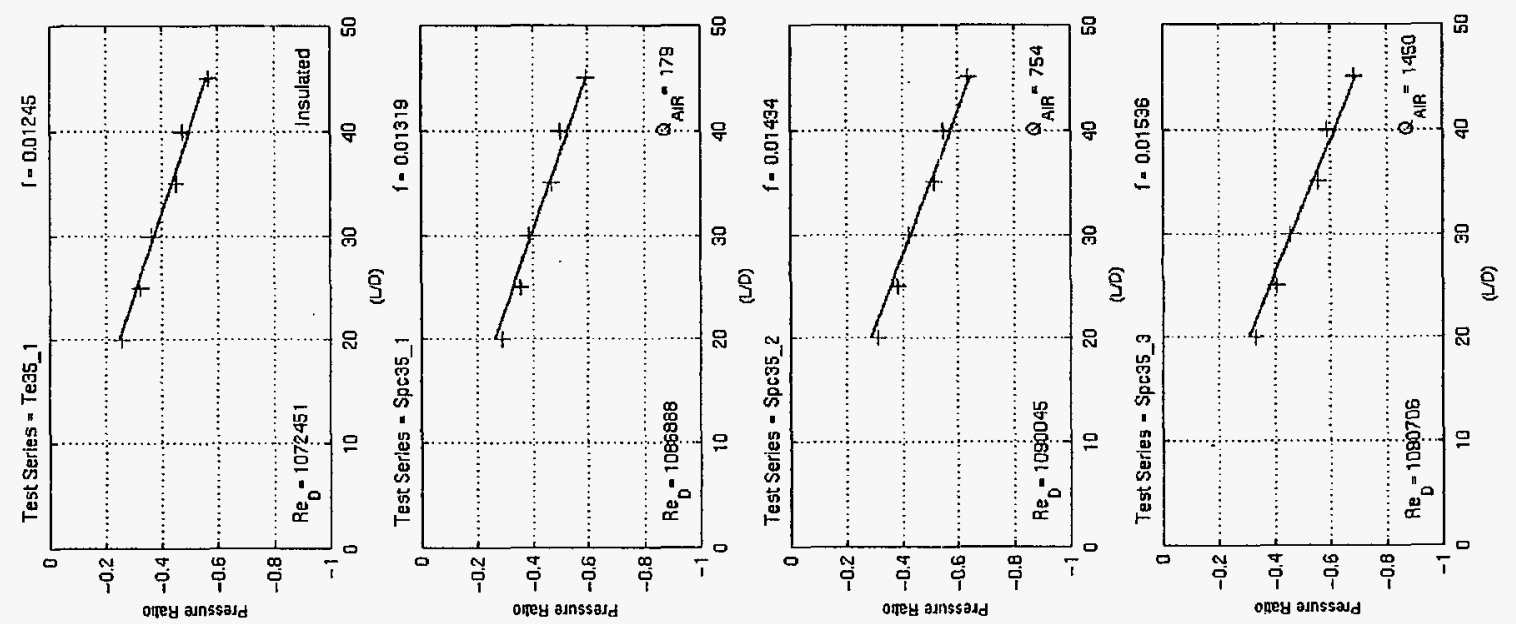

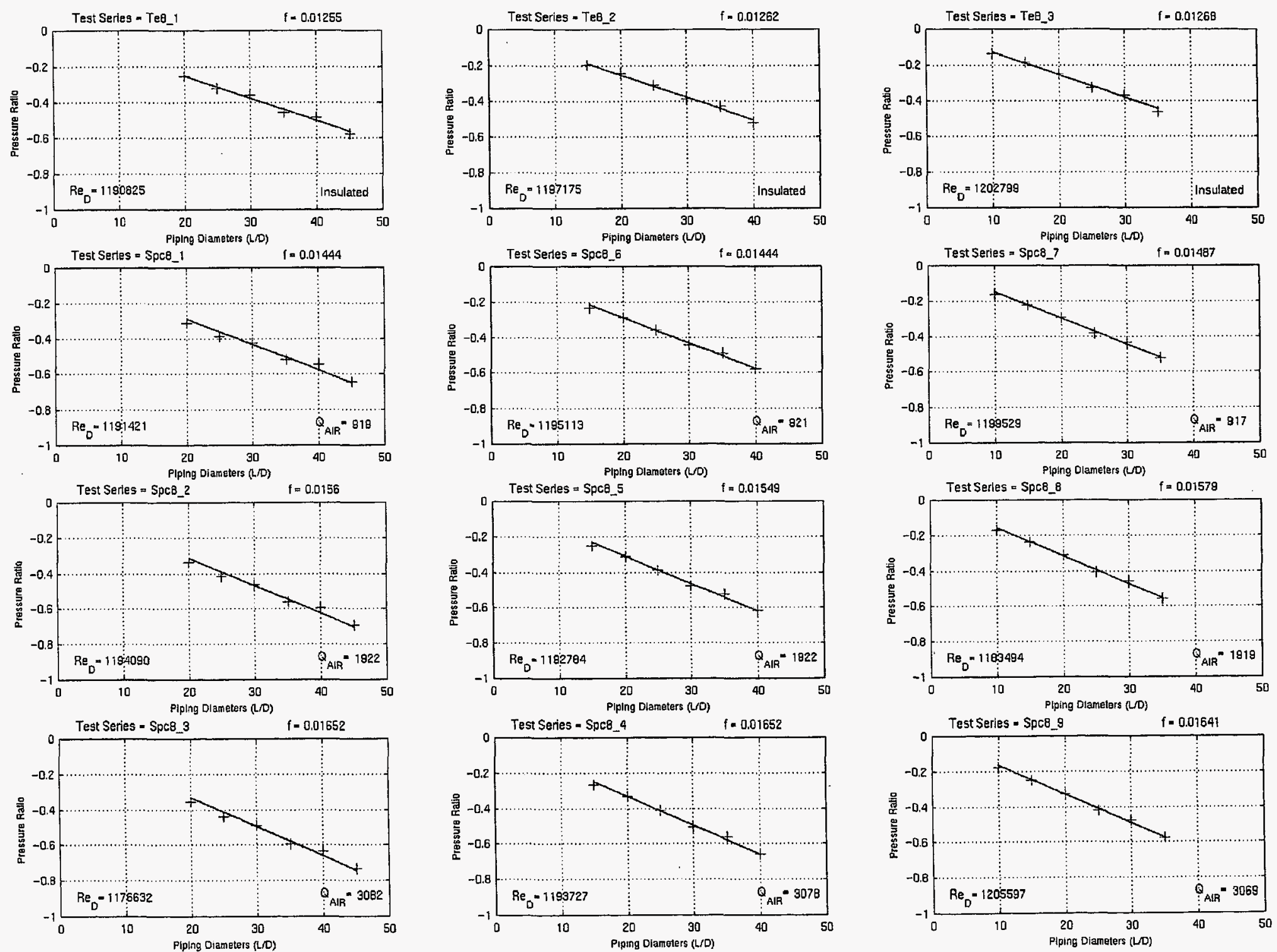

Figure C.3 Reynolds number range: $1.18-1.21 \times 10^{6}$ 

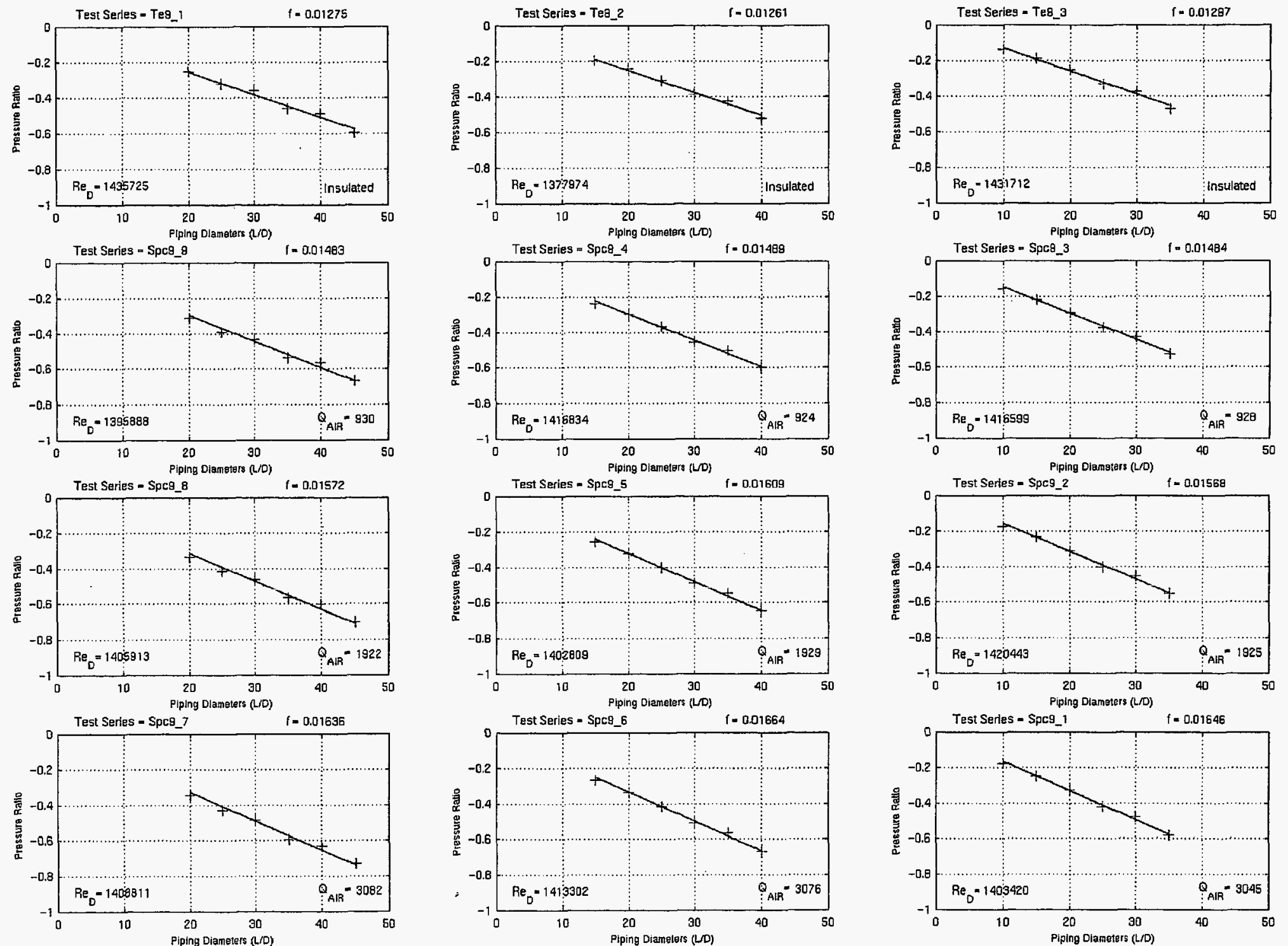

Figure C.4 Reynolds number range: $1.38-1.44 \times 10^{6}$ 

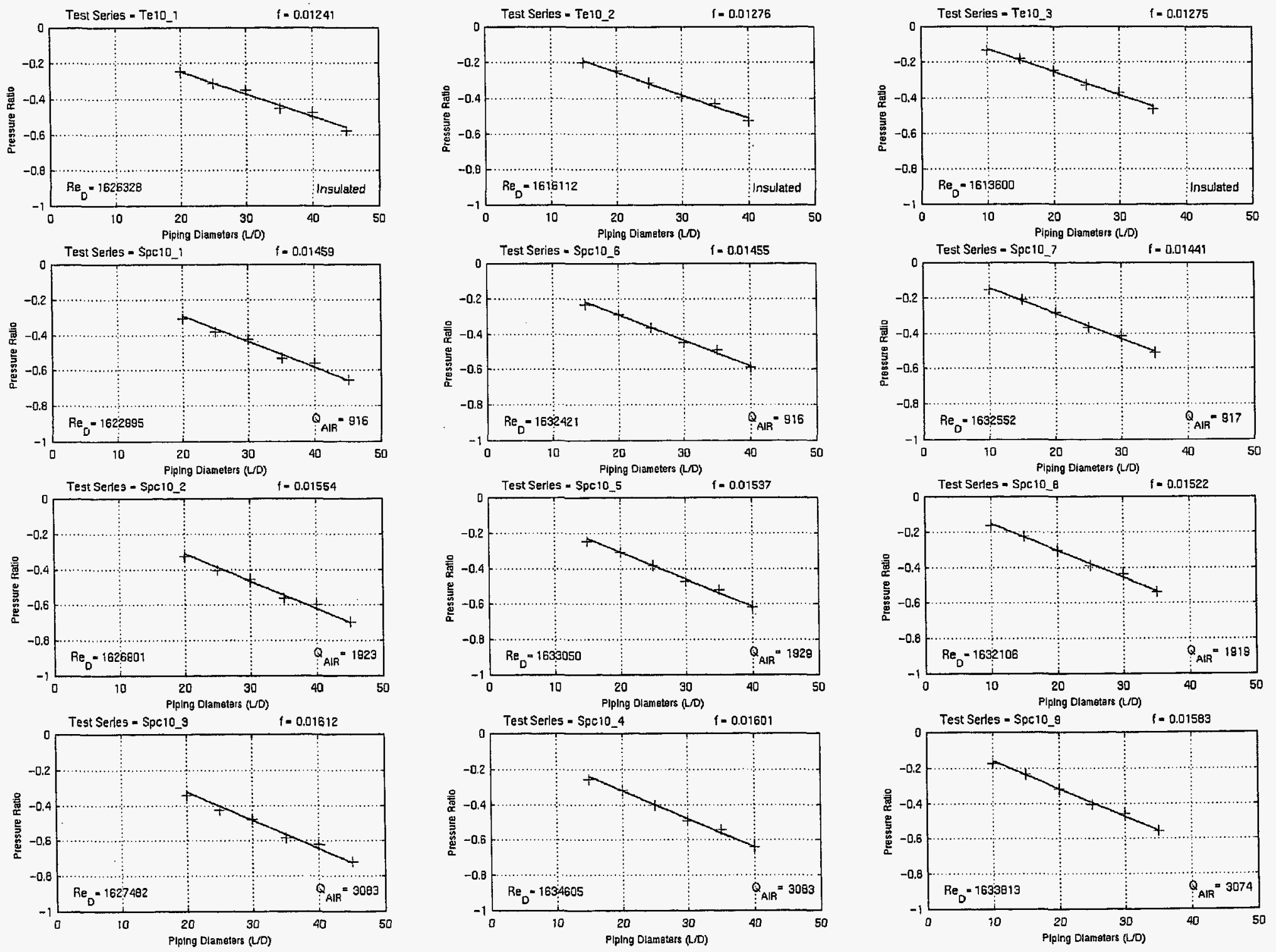

Figure C.5 Reynolds number range: $1.62-1.64 \times 10^{6}$ 

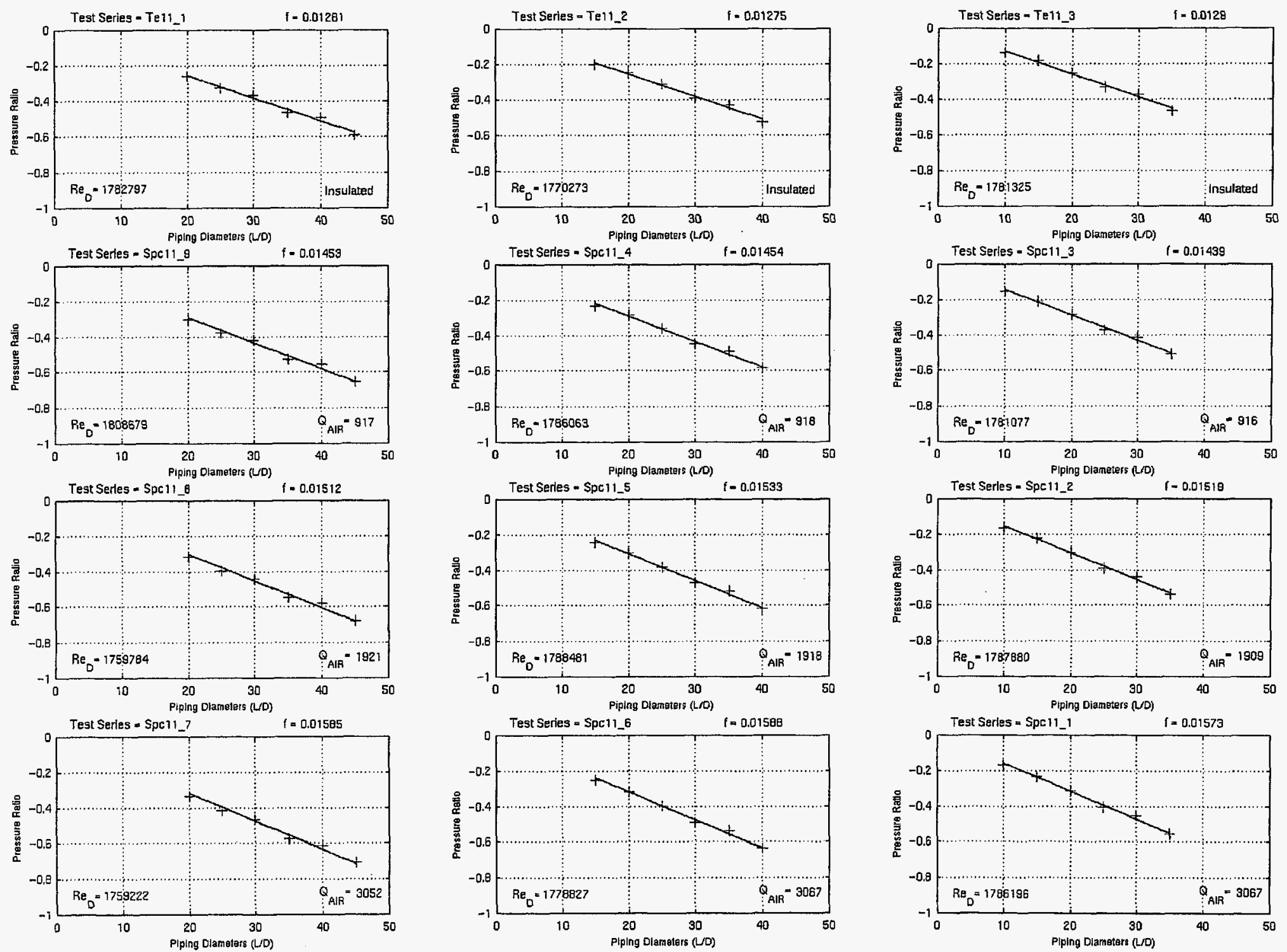

Figure C. 6 Reynolds number range: $1.75-1.81 \times 10^{6}$ 

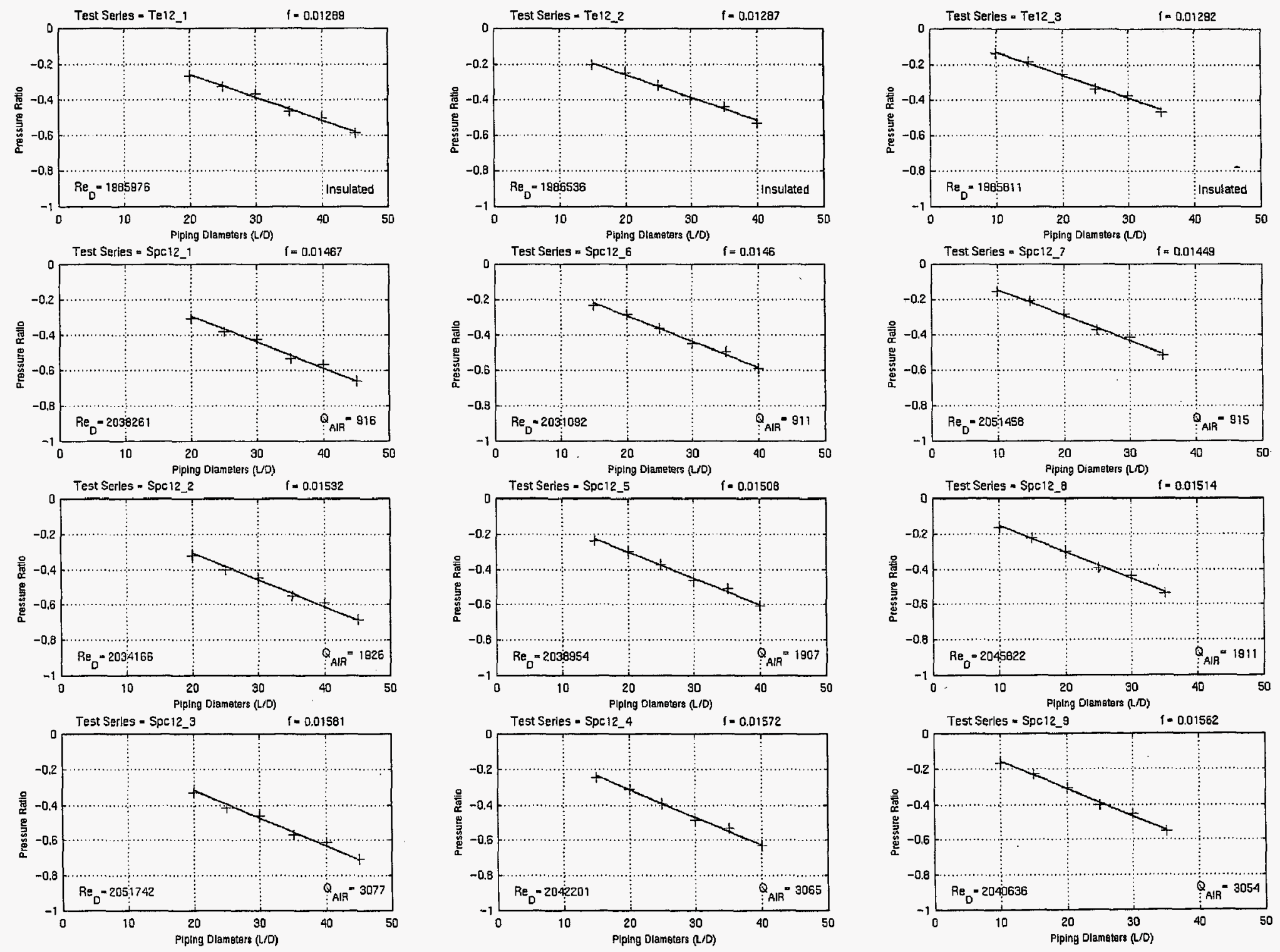

Figure C.7 Reynolds number range: $1.99-2.05 \times 10^{6}$ 

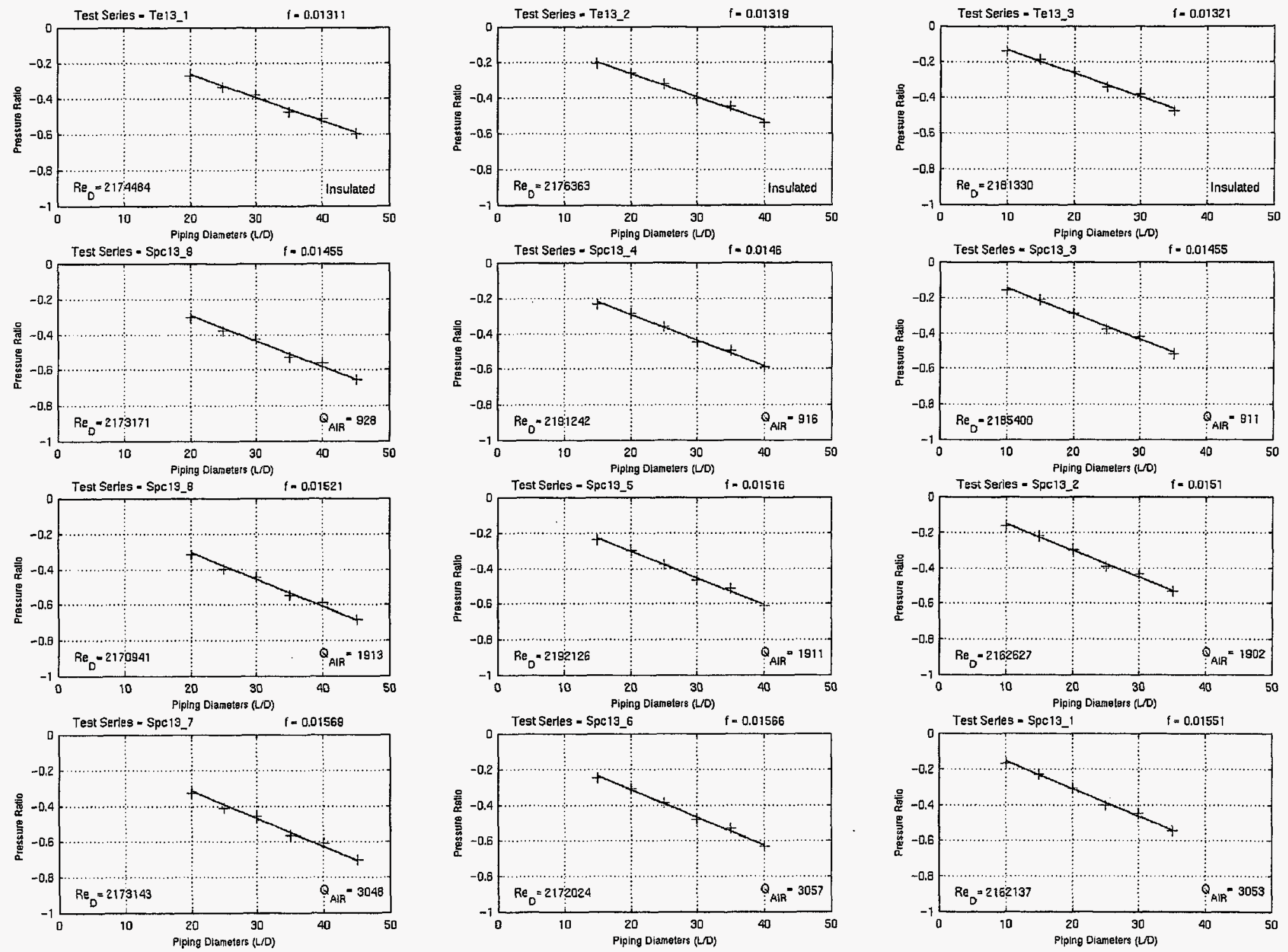

Figure C.8 Reynolds number range: $2.16-2.19 \times 10^{6}$ 

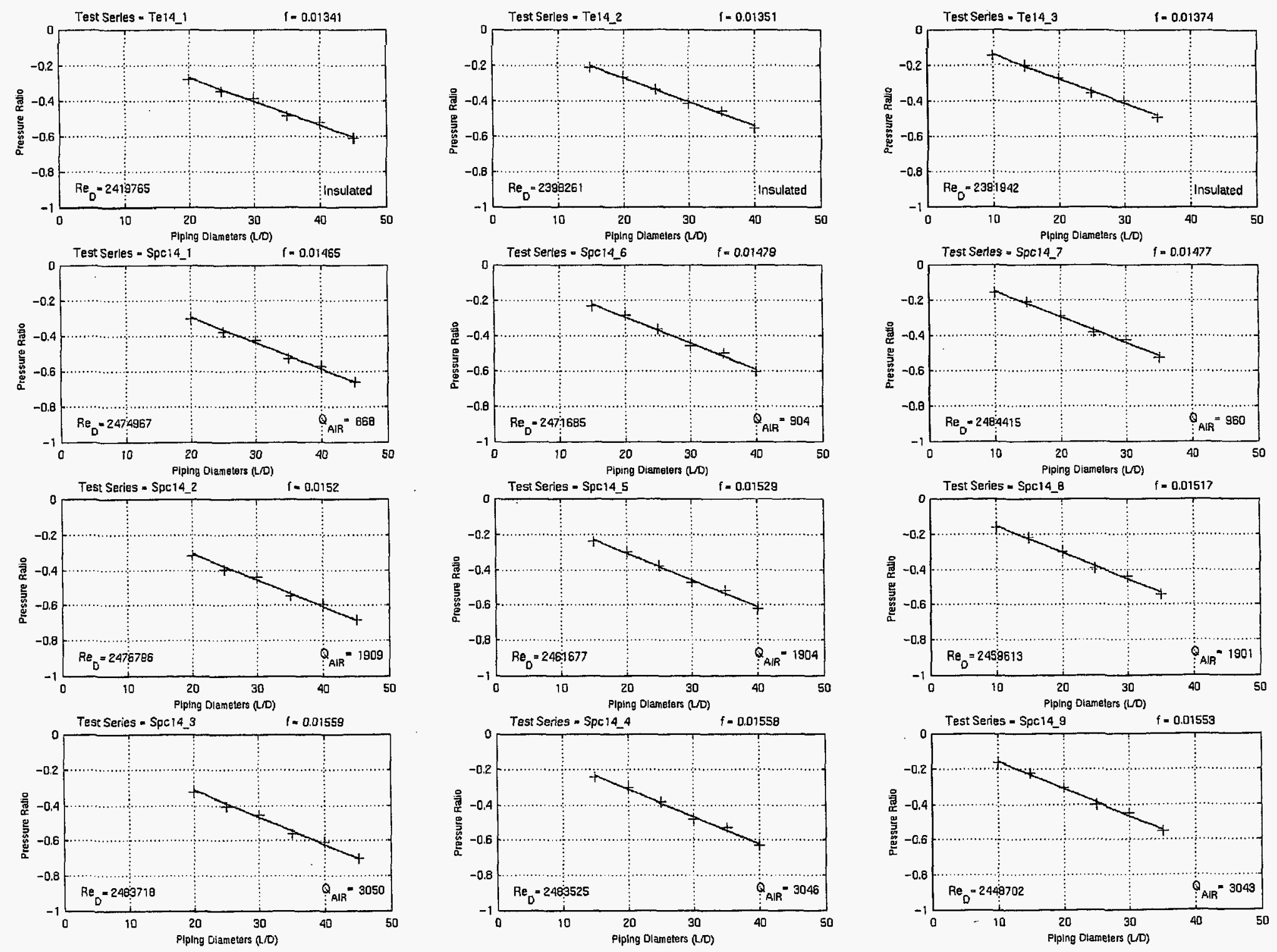

Figure C. 9 Reynolds number range: $2.39-2.48 \times 10^{6}$ 

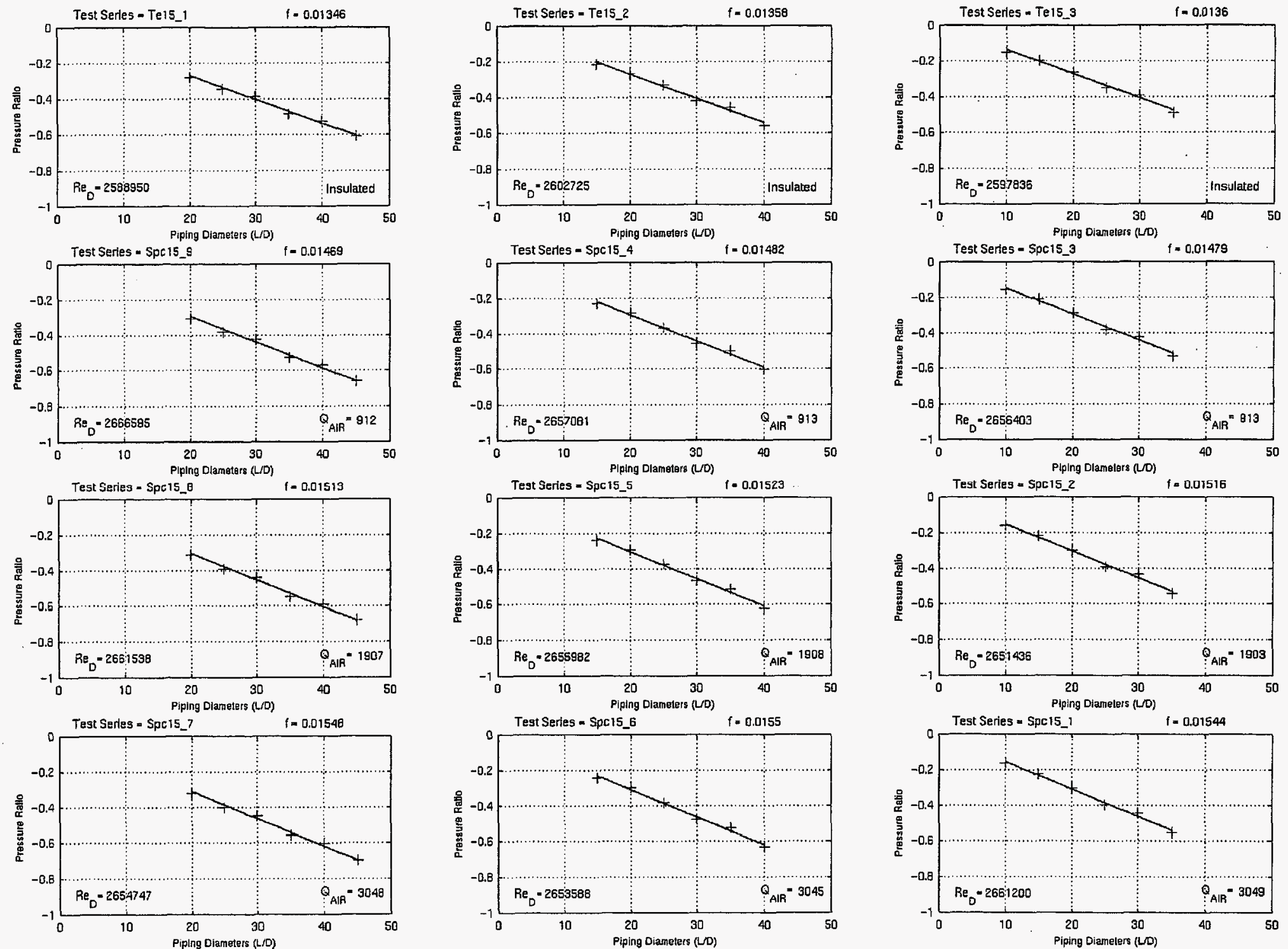

Figure C. 10 Reynolds number range: $2.59-2.66 \times 10^{6}$ 

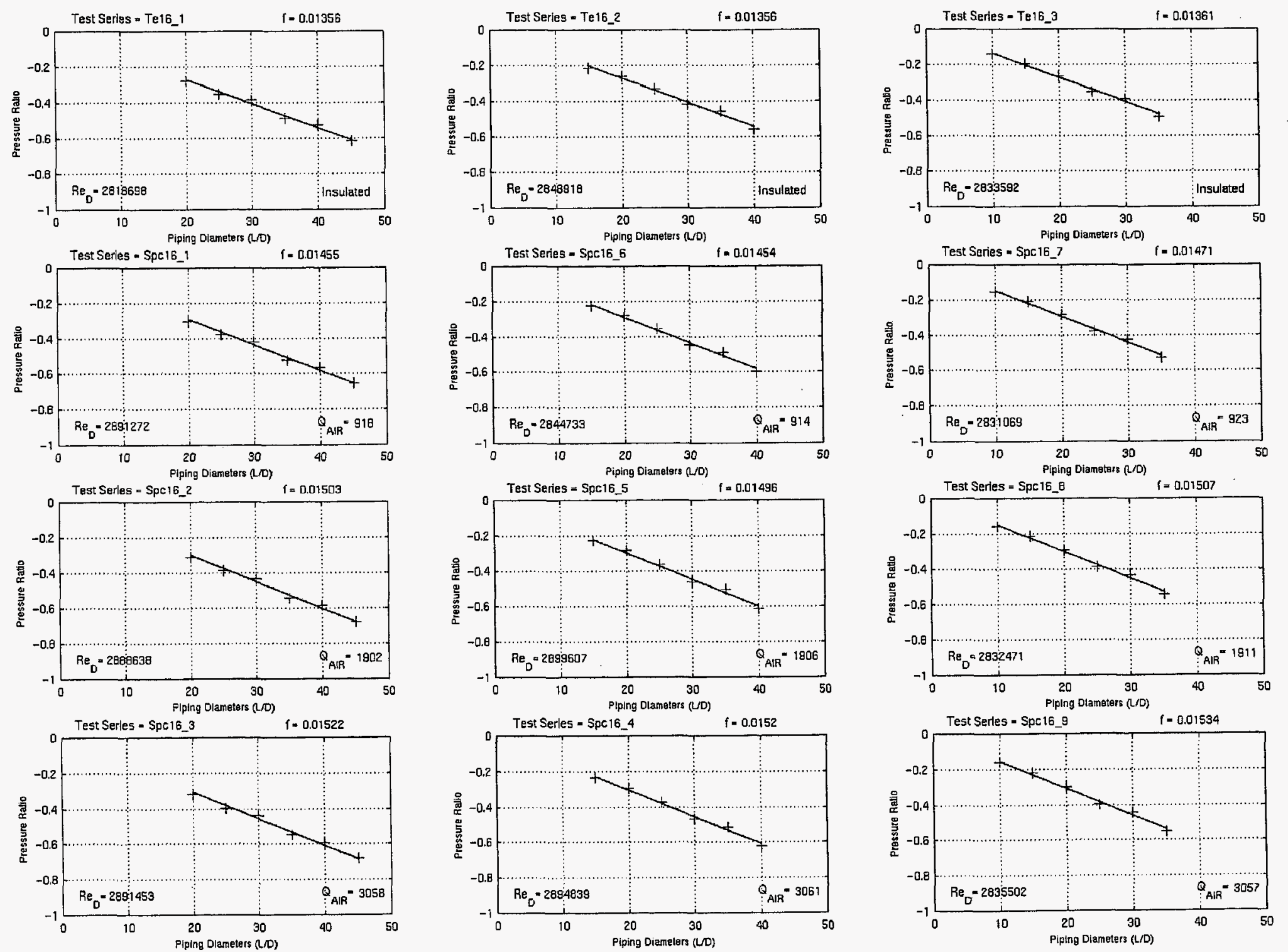

Figure C.11 Reynolds number range: $2.81-2.90 \times 10^{6}$ 

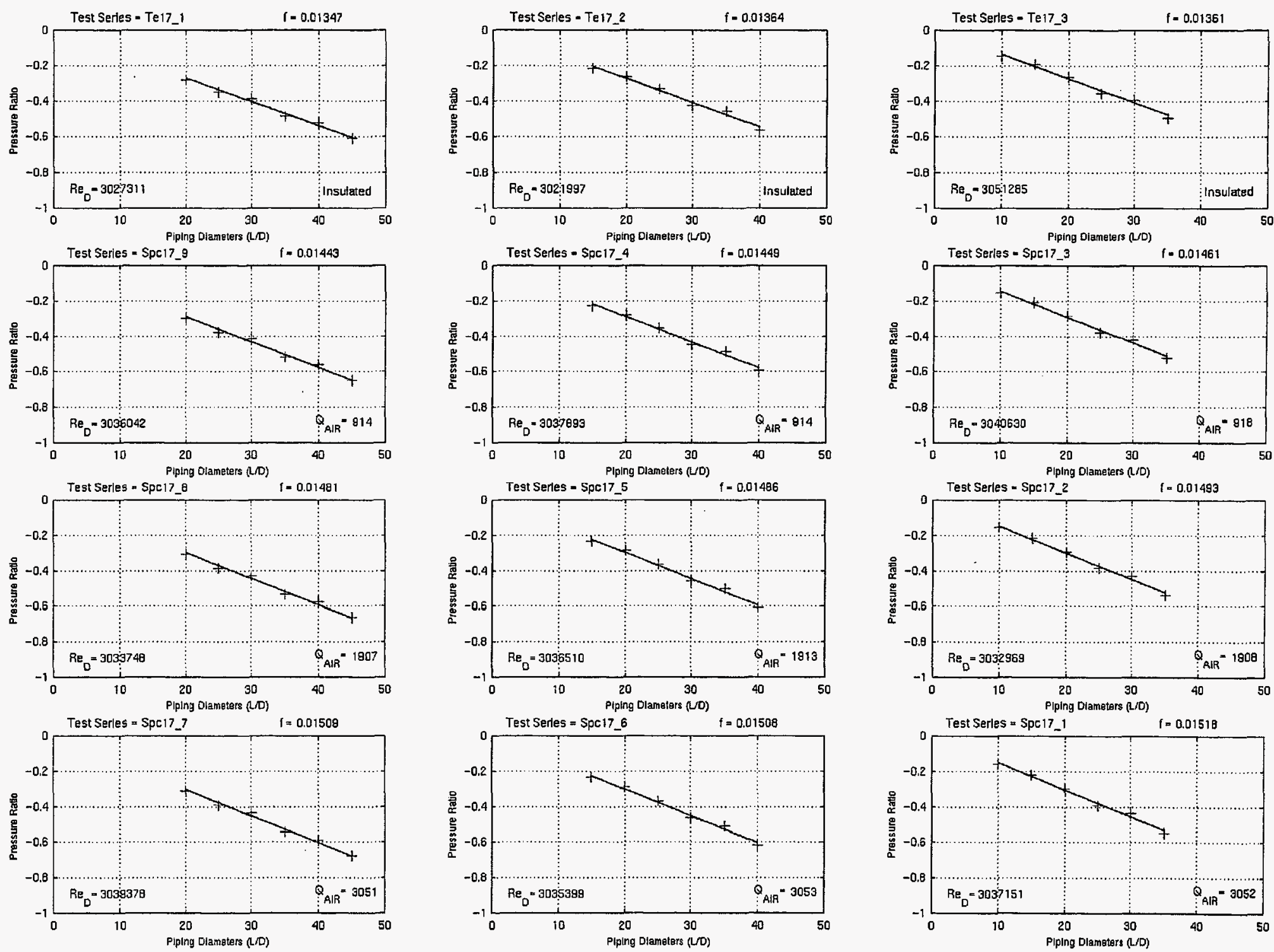

Figure C.12 Reynolds number range: $3.02-3.04 \times 10^{6}$ 

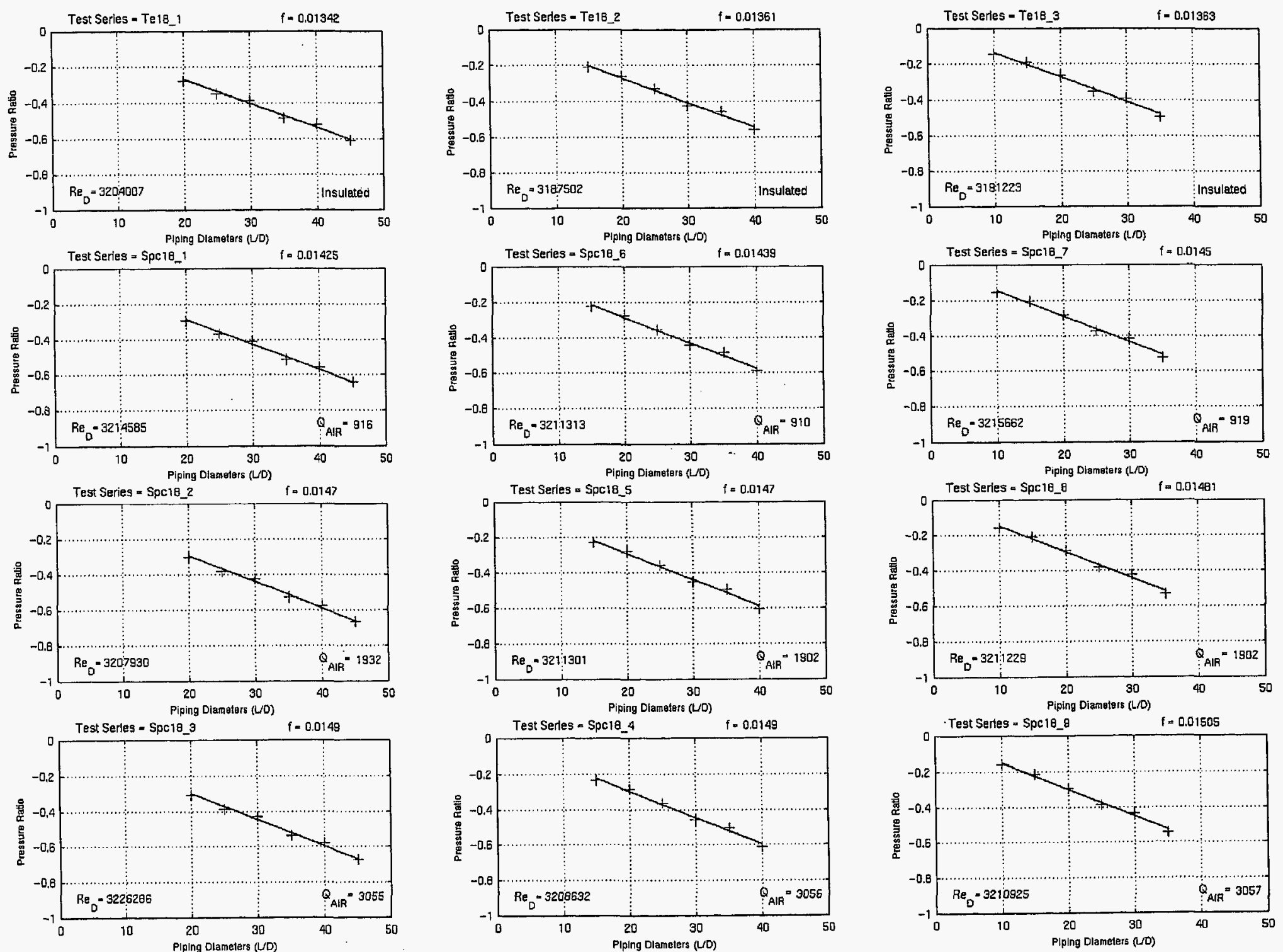

Figure C.13 Reynolds number range: $3.19-3.23 \times 10^{6}$ 

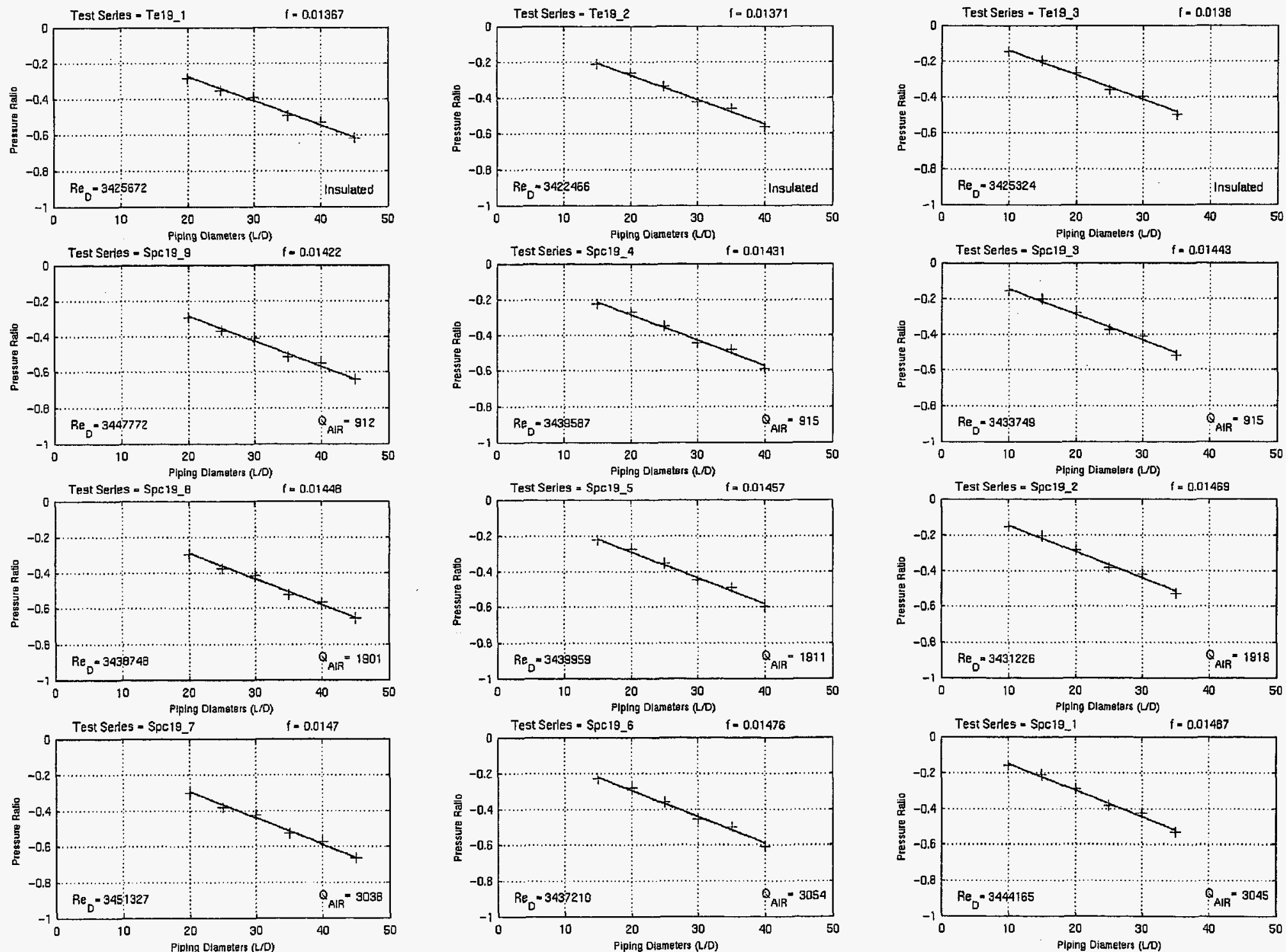

Figure C.14 Reynolds number range: $3.42-3.45 \times 10^{6}$ 

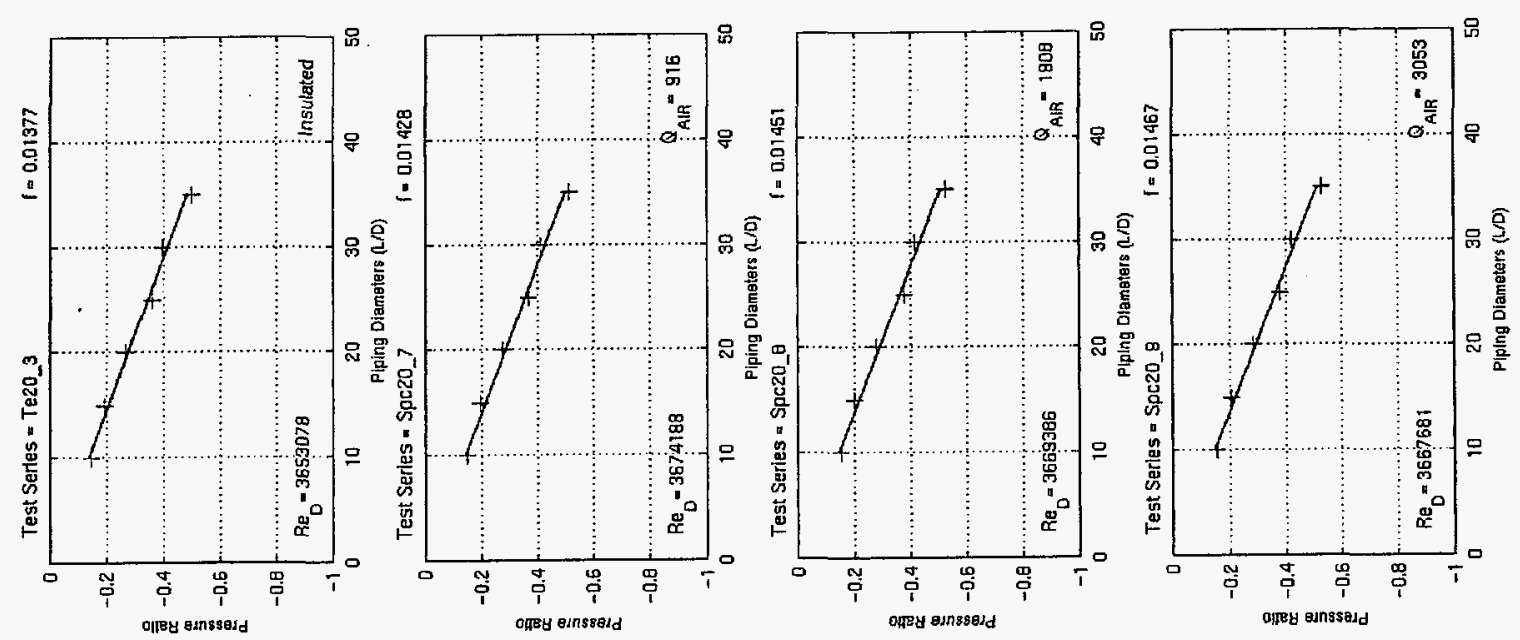

$\stackrel{\circ}{\circ}$
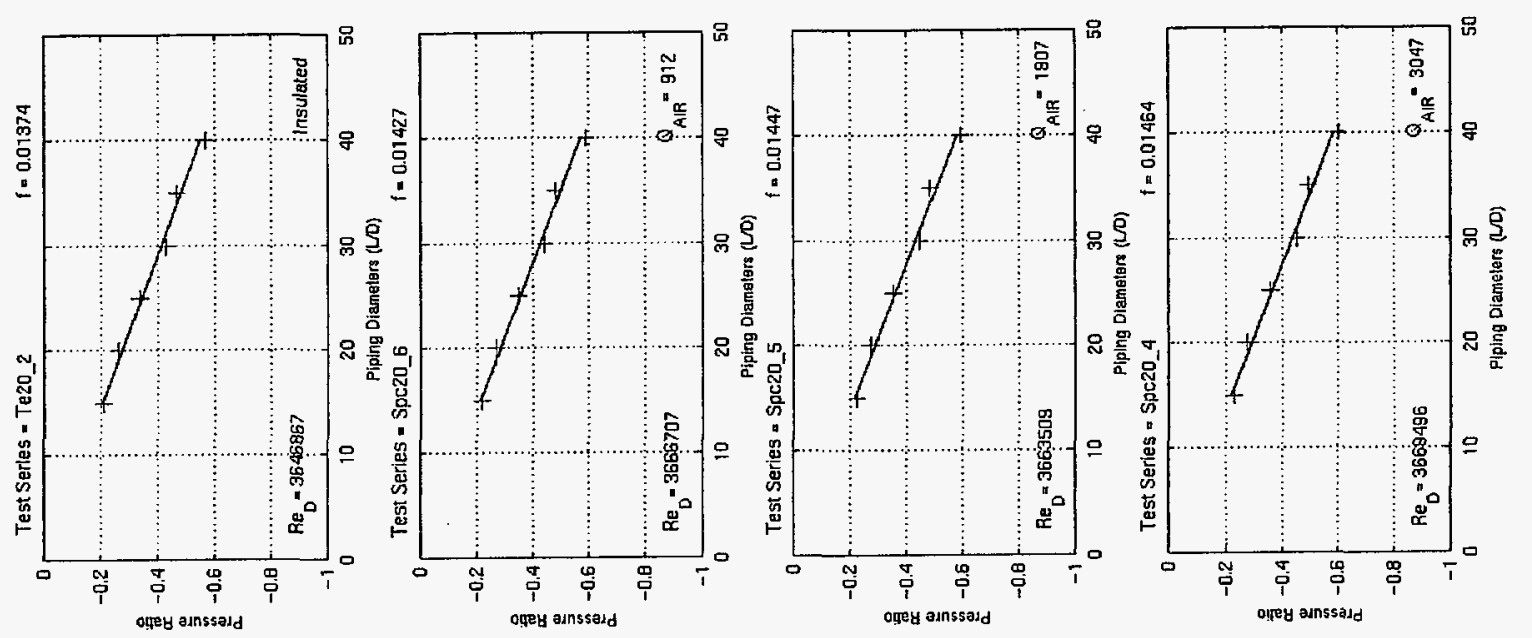

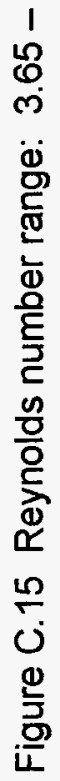
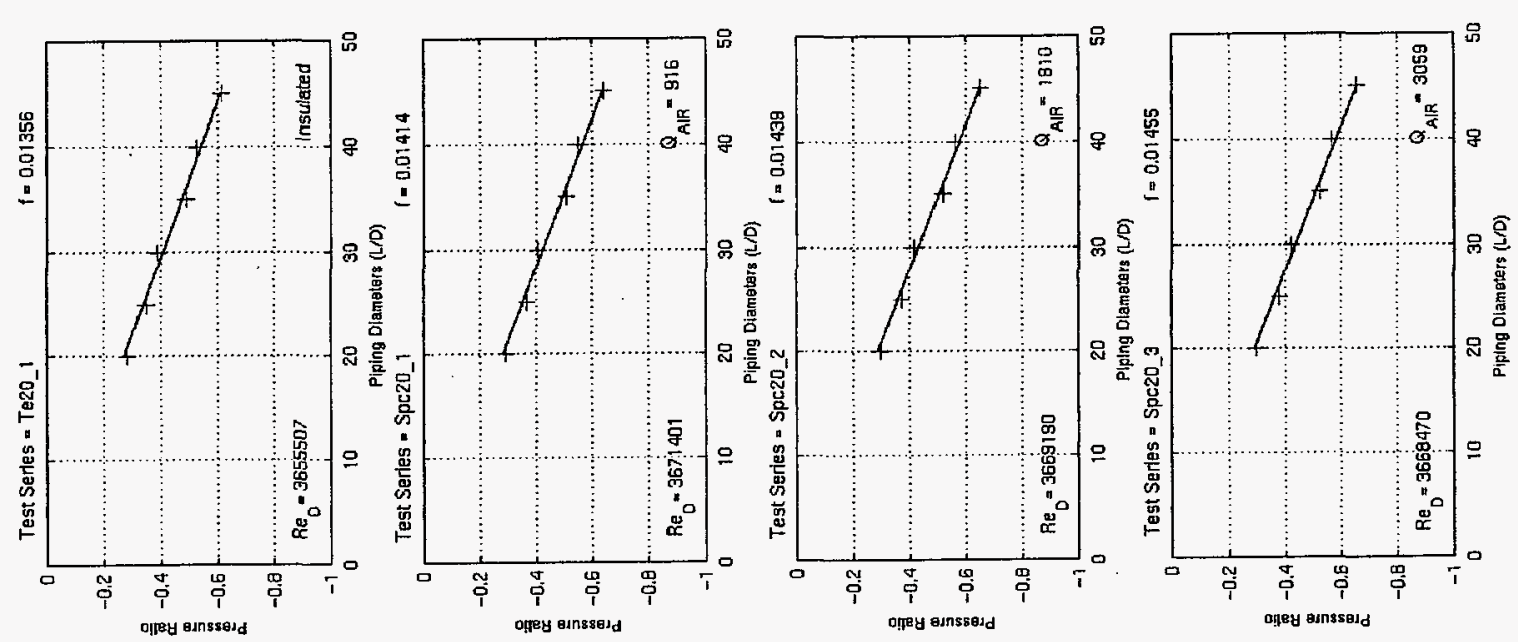

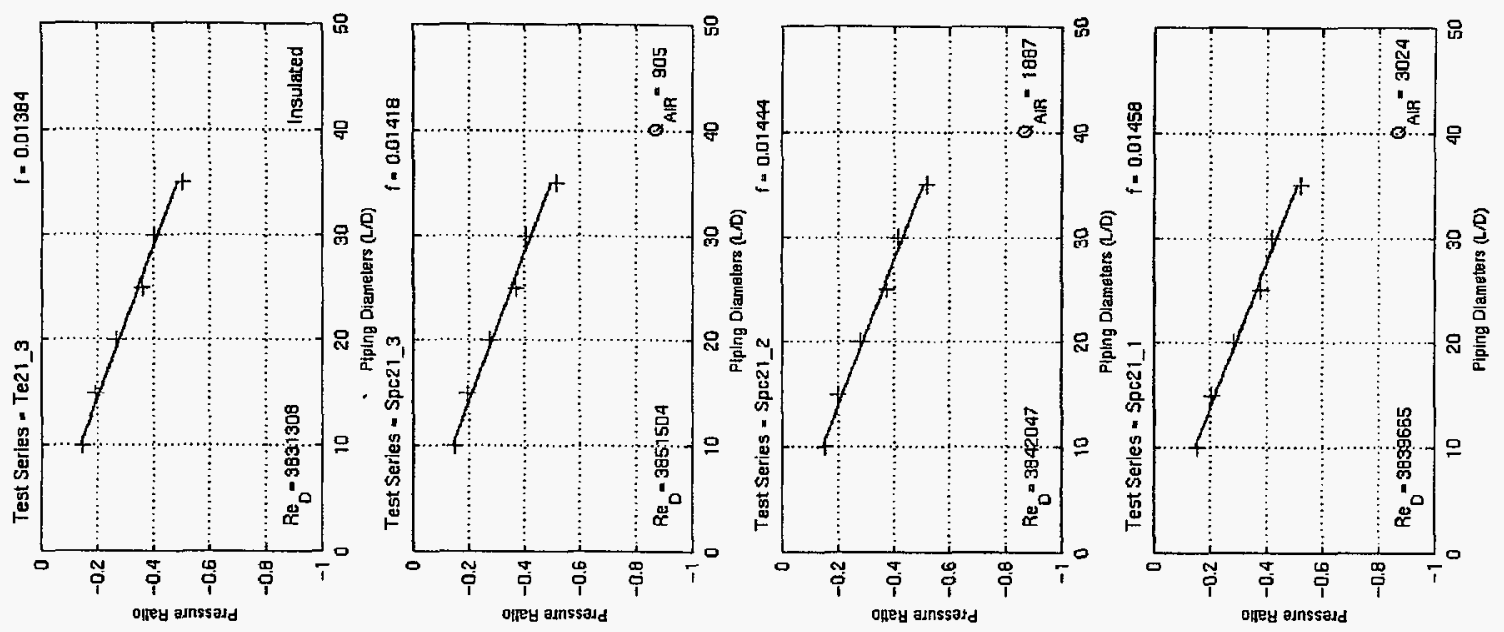

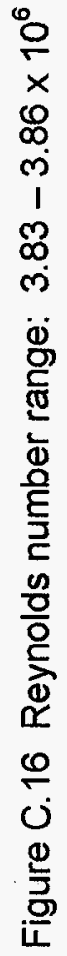
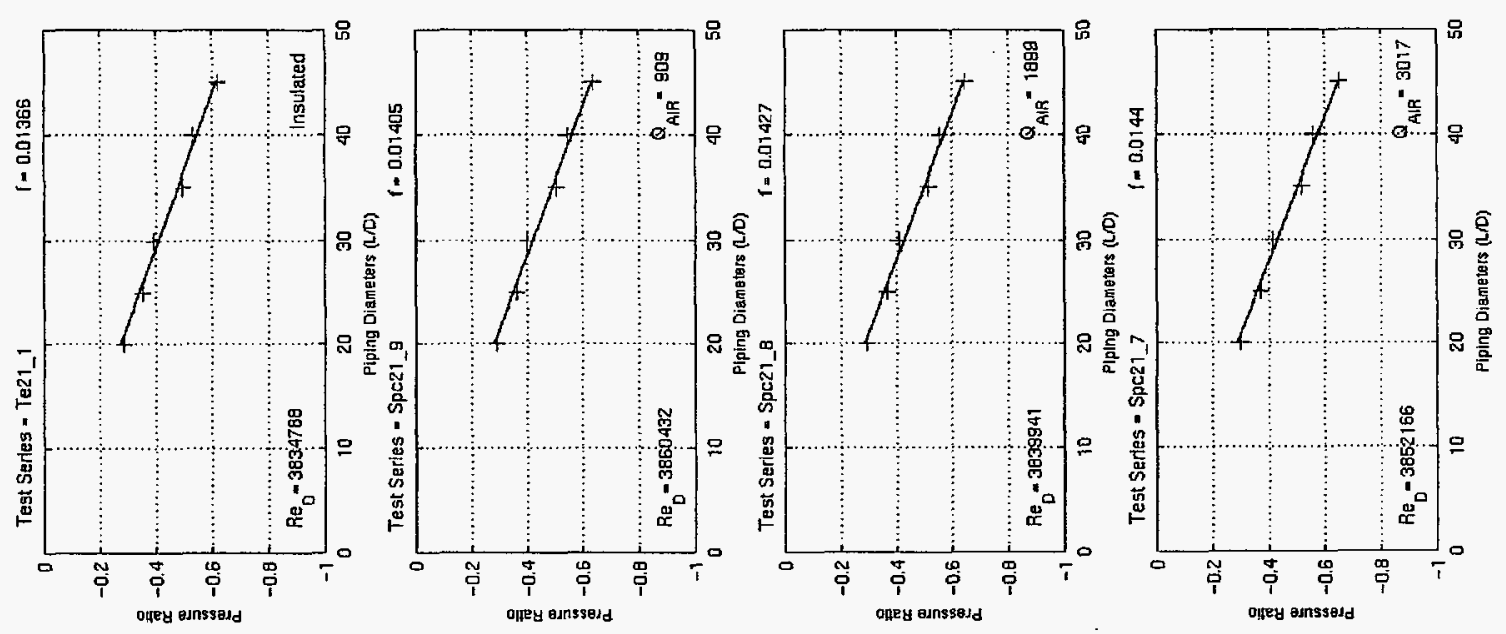

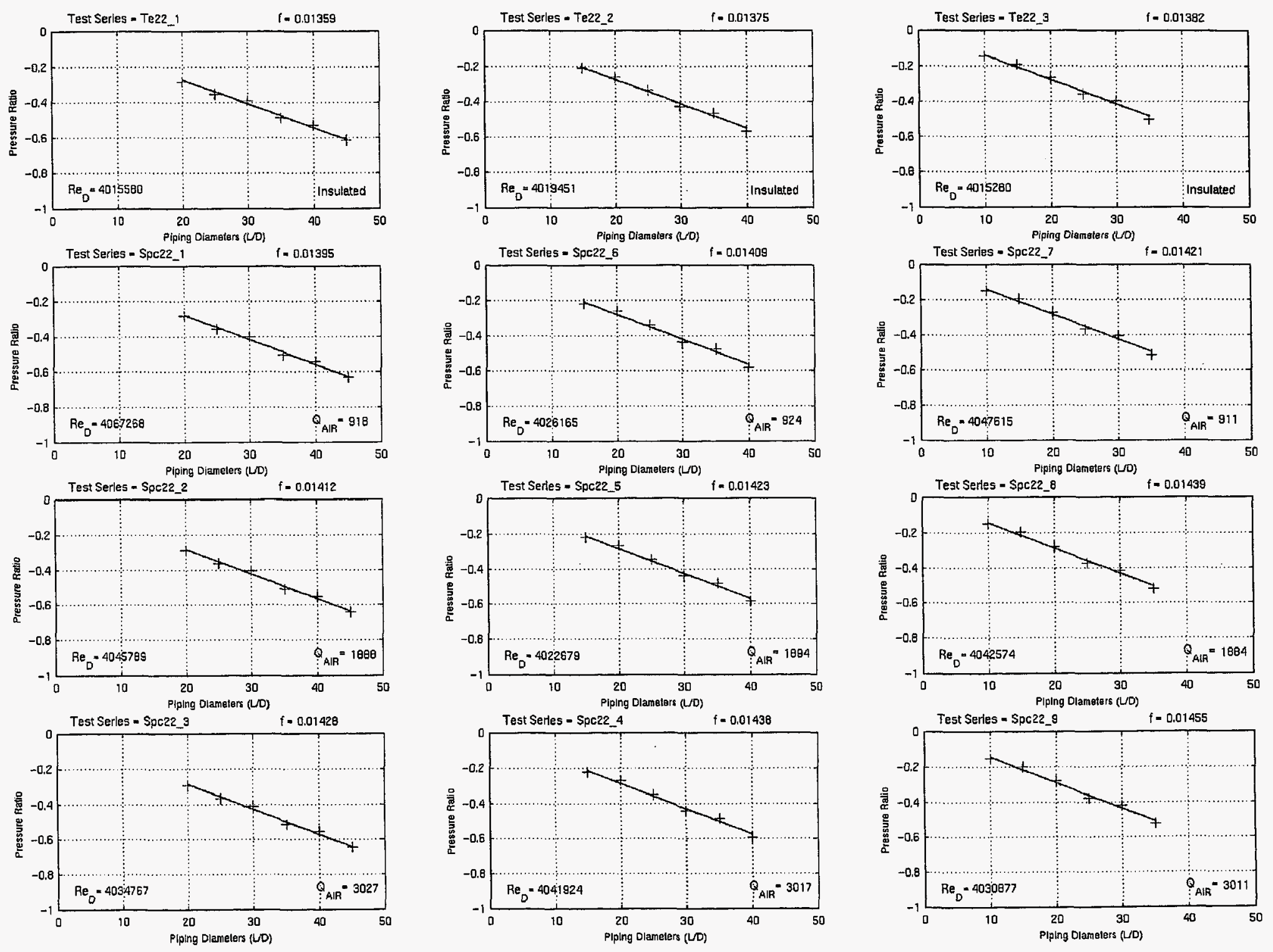

Figure C.17 Reynolds number range: $4.02-4.07 \times 10^{6}$ 

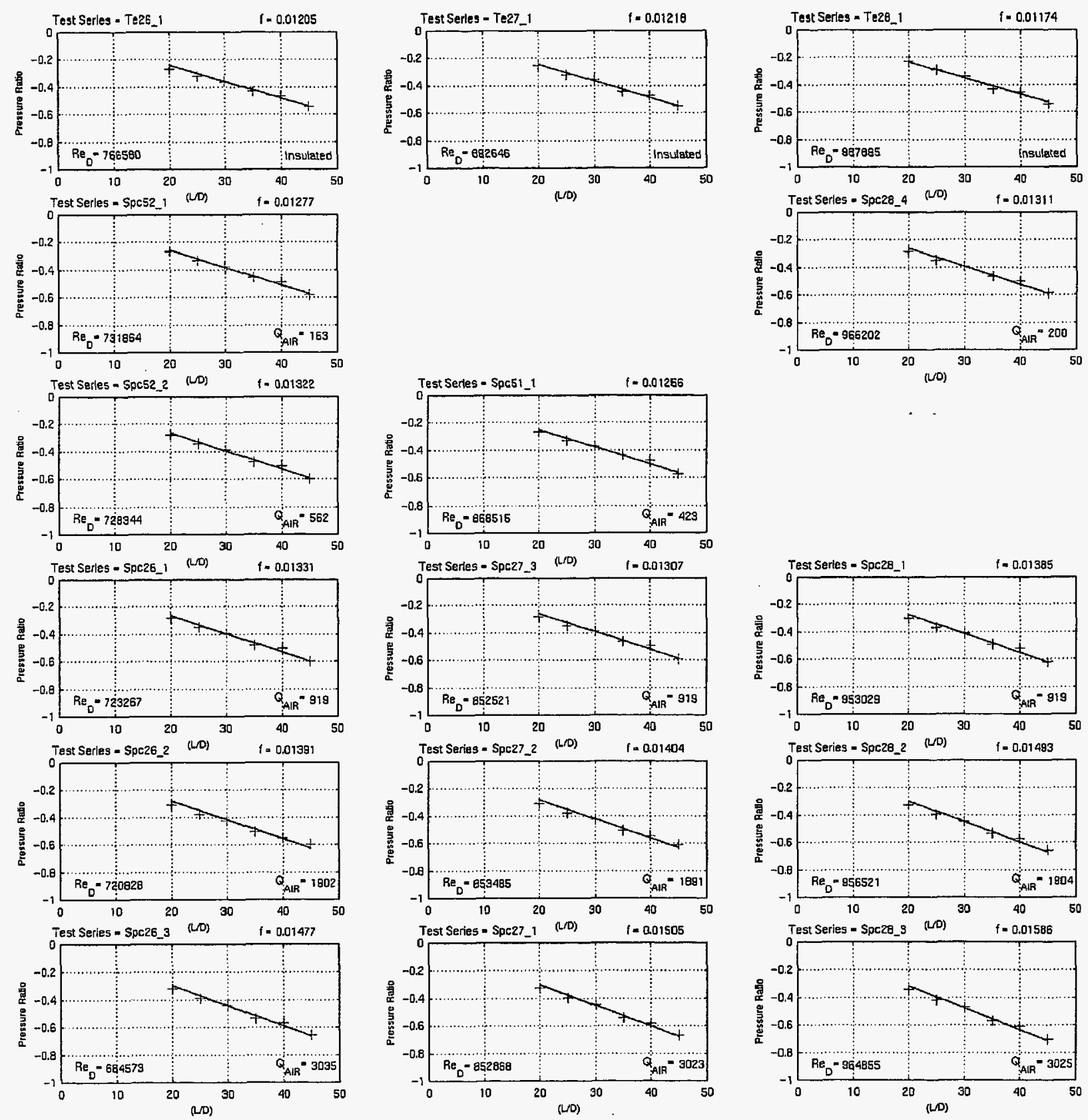

Figure C.18 Reynolds number range: $0.68-0.99 \times 10^{6}$ 

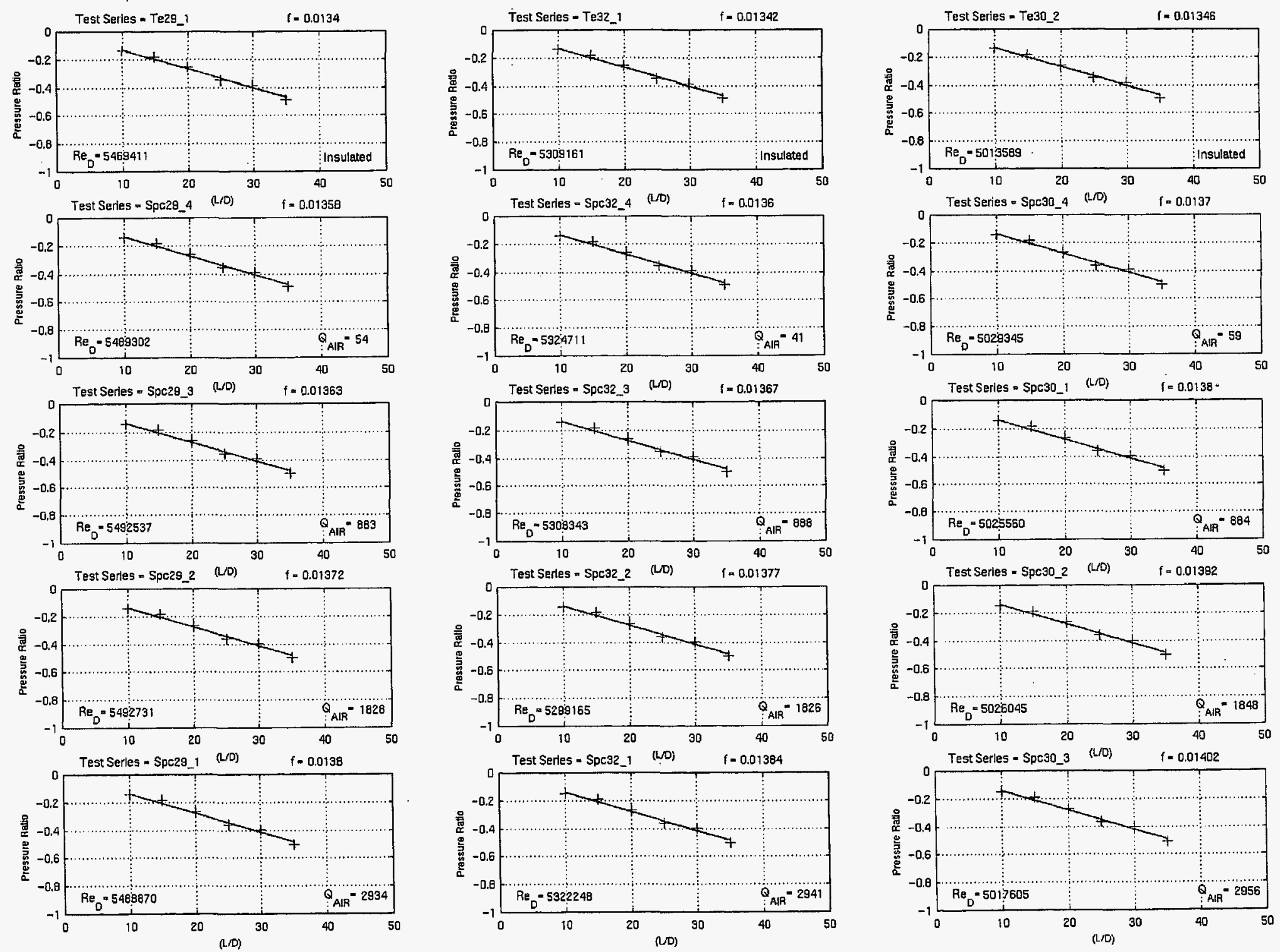

Figure C.19 Reynolds number range: $5.01-5.49 \times 10^{6}$ 


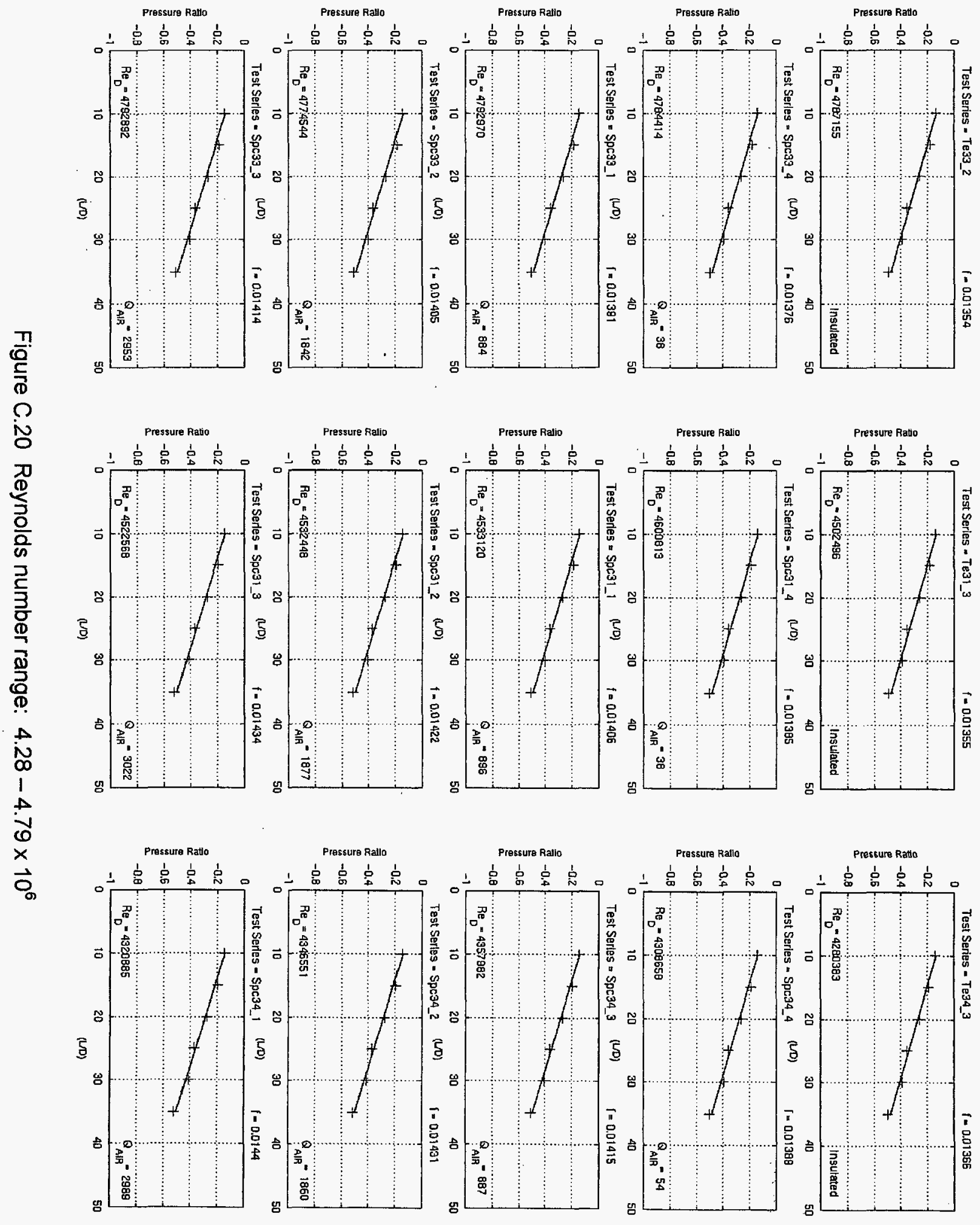

